\title{
Dendritic speeding of synaptic potentials in an auditory brainstem principal neuron
}

Geetha Srinivasan ${ }^{1}$, Andre Dagostin ${ }^{1}$, Richardson N. Leão ${ }^{2,3}$, Veeramuthu Balakrishnan ${ }^{1}$, Paul Holcomb ${ }^{4}$, Dakota Jackson ${ }^{4}$, George Spirou ${ }^{4,5}$, and Henrique von Gersdorff ${ }^{1}$

${ }^{1}$ Vollum Institute, Oregon Health and Science University, 3181 SW Sam Jackson Park Road, Portland, Oregon 97239

${ }^{2}$ Brain Institute, Universidade Federal do Rio Grande do Norte, Natal, Brazil

${ }^{3}$ Dep. of Neuroscience, Uppsala University, Uppsala, Sweden

${ }^{4}$ West Virginia University, Morgantown, West Virginia 26506

${ }^{5}$ University of South Florida, Tampa, Florida 33620

\section{Running headline: Dendritic compartments sculpt EPSPs}

Words in abstract: 246 . Number of Figures: 11

Keywords: mouse auditory brainstem; MNTB; calyx of Held; passive properties; capacitive currents; input resistance; membrane capacitance; dendrites; EPSC; EPSP; excitability; synaptic integration; synaptic currents and potentials; development.

\section{Corresponding author:}

Henrique von Gersdorff, $\mathrm{PhD}$

e-mail: vongersd@ohsu.edu

\section{Acknowledgements:}

This work was supported by RO1 NIDCD grants to (HvG) and (GS) and CNPq Brazil (RNL). 


\begin{abstract}
(246<250 words)
Principal cells of the medial nucleus of the trapezoid body (MNTB) in the mammalian auditory brainstem receive most of their strong synaptic inputs directly on the cell soma. However, these neurons also grow extensive dendrites during the first four postnatal weeks. What are the functional roles of these dendrites? We studied the morphology and growth of the dendrites in the mouse MNTB using both electron microscopy and confocal fluorescence imaging from postnatal day 9 (P9; pre-hearing) to P30. The soma of principal cells sprouted 1 to 3 thin dendrites (diameter $\sim 1.5$ microns) by P21 to P30. Each dendrite bifurcated into 2-3 branches and spanned an overall distance of about 80 to 200 microns. By contrast, at P9-11 the soma had 1 to 2 dendrites that extended for only 25 microns on average. Patch clamp experiments revealed that the growth of dendrites during development correlates with a progressive decrease in the input resistance, whereas acute removal of dendrites during brain slicing leads to higher input resistances. Accordingly, recordings of excitatory postsynaptic potentials (EPSPs) evoked by afferent fiber stimulation show that EPSP decay is faster in P21-24 neurons with intact dendrites than in neurons without dendrites. This dendritic speeding of the EPSP reduces the decay time constant 5-fold, which will impact significantly synaptic current summation and the ability to fire high-frequency spike trains. These data suggest a novel role for dendrites in auditory brainstem neurons: the speeding of EPSPs for faster and more precise output signal transfer.
\end{abstract}

\title{
Significance Statement $(119<120)$
}

Auditory circuits that compute sound localization express different types of specialized synapses. Some are capable of fast, precise and sustained synaptic transmission. As the paradigm example, principal cells of the MNTB receive a single calyx-type nerve terminal on their soma and this large excitatory synapse produces fast and brief supra-threshold EPSPs that can trigger trains of high frequency spikes. However, these neurons also extend thin and long dendrites with unknown function. We examined the relationship between dendritic morphology, passive electrical properties and EPSP waveform. We found that more mature neurons with intact dendrites have lower input resistances and short EPSP waveforms, ideally suited for conveying precise timing information, whereas immature neurons with shorter dendrites and higher input resistance have longer lasting EPSPs.

\section{Introduction $(631<650$ words $)$}

Neurons communicate with each other via synapses that are mostly located on extended and highly branched dendritic trees (Reyes, 2001; Martina et al., 2003). The complexity of synaptic integration arises from a wide variation in neuronal soma, axonal and dendritic morphology, ion channel expression and location, and how these factors are developmentally regulated during action potential firing (Nicoll et al., 1993; Libersat and Duch, 2004; Gulledge et al., 2005). Indeed, the shape of EPSPs can be influenced by the presence of an axonal current sink, an effect termed axonal speeding of the EPSP (Mejia-Gervacio et al., 
2007). Moreover, amputation of dendrites in cerebellar Purkinje and cortical pyramidal neurons leads to an increase in input resistance and changes in neuronal excitability (Bekkers and Hausser, 2007). The morphology and membrane properties of axons, somas and dendrites can thus sculpt the EPSP waveform.

The time course of the EPSP is determined by the waveform of the depolarizing EPSC and the intrinsic membrane properties. The currents active near the resting potential of brainstem auditory neurons include voltage-independent potassium leak currents (e.g. two-pore K channels; Bernston and Walmsley, 2008), voltage-gated low-threshold potassium current ( $\mathrm{I}_{\mathrm{KLT}}$; Manis and Marx, 1991; Brew and Forsythe, 1995) and hyperpolarization-activated cation currents $\left(\mathrm{I}_{\mathrm{h}}\right.$; Golding et al., 1995). Together these currents determine the input resistance $\left(\mathrm{R}_{\mathrm{i}}\right)$ and contribute to the membrane time constant $\left(\tau_{\mathrm{M}}\right)$, which shapes the neuron's voltage response to the EPSC. Specialized time-coding auditory brainstem neurons can have very low $\mathrm{R}_{\mathrm{i}}$ and fast $\tau_{\mathrm{M}}$ (Scott et al., 2005). In fact, some avian and mammalian neurons can have an extremely fast EPSP time course that is nearly identical to that of the EPSC (MacLeod and Carr, 2012).

The medial nucleus of the trapezoid body (MNTB) is one of the several nuclei in the superior olivary complex of mammals. MNTB neurons fire at very high frequencies and phase-lock to the presynaptic input or to its temporal envelope (Spirou et al., 1990; Wu and Kelly, 1993; von Gersdorff \& Borst 2002; Tollin, 2003). The MNTB is classically thought to function as a relay station between the cochlear nucleus (CN) and the lateral and medial superior olives, playing a major role among those brainstem nuclei that are involved in binaural hearing (Kandler and Friauf, 1993; Smith et al., 1998). The thick caliber and myelinated axons of the globular bushy cells of the anterior ventral $\mathrm{CN}$ form giant synaptic terminals called calyces of Held on the soma of MNTB principal cells (Morest, 1973; Kuwabara et al., 1991). The calyx of Held covers a large fraction of the MNTB cell soma where it forms multiple heterogeneous active zones (Rowland et al., 2000; Sätzler et al., 2002; Hoffpauir et al., 2006; Spirou et al., 2008). The large number of active zones results in large amplitude EPSCs that ensure rapid and secure synaptic transmission during repetitive afferent fiber stimulation (Taschenberger et al., 2002; Lorteije et al., 2009; Fekete et al., 2019), although synaptic inhibition can cause spike failures (Kopp-Scheinpflug et al., 2011).

The adult MNTB principal cell also has extensive dendrites (Banks and Smith, 1992; Sommer et al. 1993), which contain $\mathrm{Na}^{+}$and $\mathrm{K}^{+}$channels that contribute to neuronal excitability (Leão et al., 2008; Elezgarai et al., 2003). How dendritic properties change during early postnatal development and whether these properties contribute to synaptic integration remains poorly understood in the MNTB. Here we study the morphology of P9 to P24 MNTB dendrites using confocal microscopy and we compare this to more mature P30 neurons using EM reconstructions. We show that immature P9-11 MNTB neurons have shorter dendrites, smaller resting membrane capacitance and higher input resistance than P21-28 neurons that extend long and thin dendrites. Importantly, we found that more mature P21-24 MNTB neurons with intact dendrites have significantly faster EPSP decay kinetics than P21-24 neurons without long dendrites. Our computer modeling shows that a long and thin dendrite with a large leak conductance can produce faster 
EPSP decays. We therefore propose that MNTB neurons sprout a dendritic tree during early postnatal development in part to reduce input resistance and decrease their membrane time constant and, thus, speed EPSP decay times.

\section{Materials and Methods}

All experiments were performed according to protocols approved by the Oregon Health and Science University and University of West Virginia IACUC (Institutional Animal Care and Use Committee) in accordance with NIH guidelines.

Brainstem slice preparation: Acute brainstem slices were prepared from postnatal day 5 (P5) to P24 mice pups of either sex (C57BL/6J strain; Charles River Laboratories, Wilmington, MA). After decapitation, the brainstem was quickly immersed in ice-cold low calcium artificial cerebrospinal fluid (aCSF) containing (in mM): $125 \mathrm{NaCl}, 2.5 \mathrm{KCl}, 3 \mathrm{MgCl}_{2}, 0.1 \mathrm{CaCl}_{2}, 25$ glucose, $25 \mathrm{NaHCO}_{3}, 1.25$ $\mathrm{NaH}_{2} \mathrm{PO}_{4}, 0.4$ ascorbic acid, 3 myo-inositol, 2 Na-pyruvate, pH 7.4-7.5 when bubbled with carbogen (95\% $\mathrm{O}_{2}, 5 \% \mathrm{CO}_{2}$ ) and having osmolarity of 310-320 mOsm. For older animals (P21-24), the entire procedure was performed in room temperature. Transverse slices of the auditory brainstem were cut at a thickness of $200 \mu \mathrm{m}$ using a vibratome slicer (VT1000; Leica, Bannockburn, IL), and incubated at $37^{\circ} \mathrm{C}$ for $30 \mathrm{~min}$ in normal aCSF and thereafter kept at room temperature $\left(22-24^{\circ} \mathrm{C}\right)$ for experiments. The normal aCSF was the same as the low-calcium aCSF except that $1 \mathrm{mM} \mathrm{MgCl}$ and 1.2 or $2 \mathrm{mM} \mathrm{CaCl}_{2}$ were used.

Patch-clamp electrophysiology: After incubation, slices were transferred to a $1 \mathrm{ml}$ chamber and perfused with normal aCSF at the rate of 1.5-2 $\mathrm{ml} / \mathrm{min}$. Medial nucleus of the trapezoid body (MNTB) neurons were viewed using a Zeiss Axioskop 2 FS microscope equipped with differential interference contrast (DIC), and a 40x water-immersion objective. To perform whole-cell recordings from MNTB neurons, we used an intracellular solution containing the following (in $\mathrm{mM}$ ): $130 \mathrm{~K}$-gluconate, $20 \mathrm{KCl}, 5$ $\mathrm{Na}_{2}$-phosphocreatine, $10 \mathrm{HEPES}, 5$ EGTA, $4 \mathrm{Mg}$-ATP, and $0.5 \mathrm{GTP}$, pH adjusted to 7.3 with $\mathrm{KOH}$, and 300-305 mOsm. In addition, 4 mM QX-314 was added in the internal solution to measure excitatory postsynaptic currents (EPSCs) and potentials (EPSPs). All salts were purchased from Sigma (St. Louis, MO).

Recording pipettes were pulled from borosilicate glass capillaries (World Precision Instruments) with a Sutter P-97 electrode puller (Sutter Instruments, Novato, CA) and had open tip resistances of 2.0-3.0 $M \Omega$. Access resistance $\left(R_{s}\right)$ was $\leq 9 \mathrm{M} \Omega$ and $R_{s}$ was compensated $>85 \%$, so that the compensated $R_{s}$ was about 1-2 M . All traces for kinetic analysis and display were corrected off-line for series resistance and holding potential errors (Schneggenburger et al. 1999). For voltage-clamp recordings, the principal cells were voltage clamped at holding potential of $-70 \mathrm{mV}$ and the synaptic signals were filtered at $2.9 \mathrm{kHz}$. For analysis of passive membrane properties, capacitive currents elicited by $10 \mathrm{mV}$ hyperpolarizing voltage step were filtered at the minimum amount (filter 1 at $30 \mathrm{kHz}$ and filter 2 at $13.9 \mathrm{kHz}$ ) and the sampling rate was $100 \mathrm{kHz}$. Afferent fibers were stimulated with a bipolar platinum/iridium electrode (Frederick Haer Company, Bowdoinham, ME) placed near the midline spanning the afferent fiber tract of the MNTB. An 
Iso-Flex stimulator driven by a Master 8 pulse generator (A.M.P.I., Jerusalem, Israel) was used to deliver step pulses $(100 \mu \mathrm{s},<15 \mathrm{~V}$ DC). Except capacitive currents (see above) the voltage-clamp and currentclamp data were acquired at 10 or $25 \mu$ s sampling rate using an EPC-9/2 or EPC-10/2 amplifier (HEKA Elektronik, Lambrecht, Germany) controlled by Pulse 8.4 or PatchMaster software and filtered on-line at $2.9 \mathrm{kHz}$.

Confocal fluorescence microscopy: MNTB neurons were filled with Alexa fluor $555(250 \mu \mathrm{M})$ via the patch pipette for at least $20 \mathrm{~min}$. The $200 \mu \mathrm{m}$ thick brainstem slices were subsequently fixed in $4 \%$ (wt/vol) paraformaldehyde in phosphate buffer solution (PBS) overnight at $4^{\circ} \mathrm{C}$. Slices were then washed in PBS three times, and each wash lasted about $15 \mathrm{~min}$, and the slices were then mounted onto superfrost slides in photobleaching-protective medium (Gel/Mount ${ }^{\mathrm{TM}}$, biomeda corp). Stained slices were viewed with laser lines at $543 \mathrm{~nm}$ (orange red) using a 20x objective on a confocal-scanning microscope (Olympus Fluoview 300). The confocal images were analyzed using ImageJ (Wayne Rasband, NIH).

Data Analysis: Data were analyzed off-line and presented using Igor Pro (Wavemetrics, Lake Oswego, OR) and AxographX. Results are expressed as mean \pm S.E.M. The significance of differences among data sets was evaluated by Student's unpaired two-tailed $t$ test; $\mathrm{p}<0.05$ was considered as significant.

\section{Estimation of decay kinetics, capacitance and input resistance via voltage-clamp:}

Capacitive currents elicited by a voltage-clamp step of $10 \mathrm{mV}$ were fitted over a time interval of $25 \mathrm{~ms}$ with mono, bi, or tri exponential function (based on the improvement of the summed square error):

$$
D(t)=A_{\mathrm{f}} e_{\mathrm{f}}^{-t / \tau}+A_{\mathrm{med}} * e_{\mathrm{med}}^{-t / \tau}+A_{\mathrm{s}} * e_{\mathrm{s}}^{-t / \tau},
$$

where $D(t)$ is the decay of the current as a function of time $(t)$ and $A_{\mathrm{f}}, A_{\text {med }}$ and $A_{\mathrm{s}}$ are amplitude constants and $\tau_{\mathrm{f}}, \tau_{\mathrm{med}}$, and $\tau_{\mathrm{s}}$ are the fast, medium, and slow decay time constants, respectively. We first subtracted any capacitive currents in the cell-attached mode to eliminate the current due to the pipette capacitance and seal resistance. The time point used to estimate the initial amplitude of capacitive currents was taken at $0.1 \mathrm{~ms}$ after the start of the voltage-clamp jump (see Methods section of Mejia-Gervacio et al., 2007 and Nadeau and Lester, 2000; and appendix of Nadeau and Lester, 2002). The amplitudes and the time constants of the capacitive current are $\mathrm{A}_{\mathrm{f}}, \mathrm{A}_{\text {med }}, \mathrm{A}_{\mathrm{s}}$, and $\tau_{\mathrm{f}}, \tau_{\text {med }}, \tau_{\mathrm{s}}$ respectively. Individual capacitance components were estimated from:

$$
\mathrm{C}_{\mathrm{f}}=\mathrm{A}_{\mathrm{f}} \cdot \tau_{\mathrm{f}} / \mathrm{V}_{\mathrm{c}} \text { and } \mathrm{C}_{\mathrm{med}}=\mathrm{A}_{\mathrm{med}} \cdot \tau_{\mathrm{med}} / \mathrm{V}_{\mathrm{c}} \text { and } \mathrm{C}_{\mathrm{s}}=\mathrm{A}_{\mathrm{s}} \cdot \tau_{\mathrm{s}} / \mathrm{V}_{\mathrm{c}} \text {, where } \mathrm{V}_{\mathrm{c}}=10 \mathrm{mV}
$$

The cell input resistance $R_{I}=V_{c} /\left(A_{f}+A_{\text {med }}+A_{s}\right)$ and the steady-state input resistance was $R_{I s s}=V_{c} / I_{s s}$, where $I_{s s}=$ steady-state capacitive current. Membrane capacitance $\left(C_{m}\right)$ was also calculated from $C_{m}=C_{s p} x$ $\mathrm{S}$, where $\mathrm{C}_{\mathrm{sp}}=$ specific capacitance $\left(10 \mathrm{fF} / \mu \mathrm{m}^{2}\right)$ and $\mathrm{S}=$ surface area. The decays of the evoked excitatory postsynaptic currents and potentials (EPSCs and EPSPs) were fit by single- or double-exponential functions. The weighted decay time constant of the EPSC or EPSP was calculated as

$$
\tau_{\text {wd }}=\left(A_{\text {fast }} \mathrm{X} \tau_{\text {fast }}+A_{\text {slow }} \mathrm{X} \tau_{\text {slow }}\right) /\left(A_{\text {fast }}+A_{\text {slow }}\right) \text {. }
$$

Computer modeling: Based on our anatomical data, we implemented a multi-compartment model of the MNTB principal neuron to investigate the contribution of different structural compartments to synaptic integration using the NEURON simulation environment (Hines \& Carnevale, 2001; for more details of the 
specific model see Leão et al., 2008). MNTB neurons were modeled with no dendrites, or one dendrite compartment with various lengths and the diameters $(\varnothing)$ set to $3 \mu \mathrm{m}$ emerging from a spherical soma $(\varnothing=$ $20 \mu \mathrm{m})$. We also included a cylindrical axonal compartment originating at the soma $(\mathrm{L}=20 \mu \mathrm{m}, \varnothing=2 \mu \mathrm{m})$. Each dendritic (and axonal) cylinder was divided into 10 isopotential compartments connected by axial resistances $(150 \Omega / \mathrm{cm})$. All the compartments were passive and we implemented various leak conductances with reversal potentials equal to the resting potential of the cell $(-65 \mathrm{mV})$. In addition, we implemented a single short EPSP provided by a calyceal input connected to the MNTB soma using the calyx of Held model of Graham et al (2001) and Hennig et al., 2008.

EM segmentation and 3D Reconstruction from SBEM: Segmentation of MNTB principal cells, dendrites and axons was performed on a serial block-face scanning electron microscopy (SBEM) image volume collected by the National Center for Microscopy and Imaging Research (NCMIR, University of California: San Diego) at P30. This image volume measured $154.81 \mu \mathrm{m}$ x $77.51 \mu \mathrm{m}$ x $142.3 \mu \mathrm{m}$ with pixel dimension of $4 \mathrm{~nm}$ in $\mathrm{X}$ and $\mathrm{Y}$, and a slice thickness of $50 \mathrm{~nm}$. The image volume was taken from the medial portion of the MNTB. Segmentation was accomplished by hand using the paint brush tool in the Seg3D software (Scientific Computing and Imaging Institute, University of Utah) and 3D reconstruction was performed using the ISO command to produce isosurfaces, which were exported as VTK objects. For maximum compatibility with other software, these VTK objects were converted to OBJ format using a custom Python script. All images of 3D reconstructions were rendered using the Rhinoceros 3D software (Robert McNeel and Associates, Seattle, WA).

Dendrite length and diameter measurement: Dendrites from SBEM images were skeletonized manually using their 3D reconstructions in the syGlass virtual reality software (IstoVisio, Morgantown, WV) by placing points in the center of the reconstruction at regular intervals. Skeletons were exported in SWC format and converted to comma-separated value files (CSV) using a custom Python script. The CSV files were imported along with their respective 3D reconstructions into Rhinoceros 3D for further analysis. Polylines representing the dendrite skeleton were created using the CurveThroughPoint command, with some manual editing to separate branching paths. The resulting branch lengths were measured using the Length command, and then broken into $10 \mu \mathrm{m}$ segments beginning at the most proximal point using the Divide command. Four diameter measurements were taken at each $10 \mu \mathrm{m}$ interval by creating 4 lines perpendicular to the dendrite skeleton and at $45^{\circ}$ to one another and trimming them by the dendrite OBJ. These measurements were then averaged, resulting in one measurement at each $10 \mu \mathrm{m}$ interval. All graphs were generated using Matlab (MathWorks, Natick, Massachusetts).

\section{Results}

\section{Mouse MNTB principal cell serial block-face electron microscopy}

At the end of the fourth postnatal week the mouse auditory system is adult-like by several functional measures (Liberman and Liberman, 2016). Using serial block-face scanning electron microscopy (SBEM) 
we thus first determined the in situ dendritic morphology of P30 mouse MNTB neurons as a benchmark of adult-like neuronal morphology. We reconstructed a total of 8 principal neurons in the medial MNTB (see Materials and Methods for SBEM procedures; Figure 1A). Each neuron had one to three dendrites sprouting from the cell soma with a few (2-4) secondary branches and a fairly constant diameter of about 1.5 microns. Most of the myelinated axons aligned with one another as they exited the MNTB forming a fiber bundle (right hand side of Figure 1A). Two isolated cells (Figure 1B and 1C; white arrows) illustrate the length, thinness, and sparsity of the dendrites and their lack of profuse dendritic branching or spines. Although the main excitatory drive of the MNTB principal cell, the calyx of Held synapse, is located entirely on the cell soma, these data clearly show that dendrites remain a stable and prominent structure that is not pruned away during early development. Given the large calyx terminal on the principal cell soma, which drives large EPSPs and spikes, the functional role of dendrites becomes an important question.

We used our reconstruction of the MNTB cells to calculate the total cellular surface area and the individual contributions to this area of the cell soma, dendrites and axons within our reconstructed volume. The total average area was about $3482 \mu \mathrm{m}^{2}$ if we include the full axon area and $3043 \mu \mathrm{m}^{2}$ if we include just the axon initial segment (Table 1). About $44 \%$ of this was the soma, $40 \%$ was the dendrites, and $\sim 16 \%$ was the thin axons. The dendrites thus contributed a significant portion of the cell area. Since some of the dendrites were cut off, this is an underestimate of the dendritic contribution. These results allowed us to estimate the cell membrane capacitance $\left(\mathrm{C}_{\mathrm{m}}\right)$ using the specific capacitance of lipid bilayer membranes $(9$ to $10 \mathrm{fF} / \mu^{2}$; Gentet et al., 2000). The total $\mathrm{C}_{\mathrm{m}}$ of the MNTB principal cell is thus between $31.3 \mathrm{pF}$ to 34.8 $\mathrm{pF}$ (Table 1). Due to fixation and dehydration for EM processing we estimate that the cell surface area may shrink by $20 \%$ (see Kuba et al., 2005). Thus, the in situ living cell $\mathrm{C}_{\mathrm{m}}$ may be about 38 to $41 \mathrm{pF}$. However, myelin greatly reduces the axonal capacitance. The mature MNTB cell capacitance (with just axon initial segment) may thus be closer to 27.4 to $30.4 \mathrm{pF}$ or, after the $20 \%$ correction for shrinkage, 33 to $36 \mathrm{pF}$.

We also determined the number and location of synaptic boutons on the dendrites (Figure 2A). Synaptic inputs were sparse along the dendrites and clustered near the initial emergence of the dendrite. The number of dendritic inputs falls off as a function of distance from the soma $(\mathrm{n}=16$ dendrites from 8 MNTB cells; Figure 2B). The dendritic membrane not innervated was often contacted and covered by thin glial processes (Figure 2C and 2E). The dendrite was sometimes completely ensheathed by glial processes, which could be buffering external potassium efflux from the dendrite (Elezgarai et al., 2003).

\section{Input resistance and membrane time constant of MNTB neurons.}

Previous morphological reconstructions of MNTB principal cells with neurobiotin and HRP-injection reveal one to three dendrites that sometimes extended beyond the borders of the MNTB (3-5 week-old rats, Banks and Smith, 1992; adult rats, Sommer et al., 1993; P16 rats, Leão et al., 2008). One or two primary dendrites sprung from the soma and then bifurcated into several smaller-diameter, aspiny branches. The axon projected mostly to SPN, MSO and LSO. The input membrane resistance $\left(\mathrm{R}_{\mathrm{m}}\right)$ of the cells measured with sharp conventional electrodes and hyperpolarizing currents was about $65 \mathrm{M} \Omega$. Subsequent, patch 
clamp recordings in gerbil MNTB revealed an $\mathrm{R}_{\mathrm{m}}$ that declined with age from $130 \mathrm{M} \Omega$ at P14-16 to 115 $\mathrm{M} \Omega$ at P19-20 to $86 \mathrm{M} \Omega$ at P28-29 (Scott et al., 2005). The membrane time constant $\left(\tau_{\mathrm{M}}\right)$ was found to be stable during this developmental period $\left(\tau_{\mathrm{M}}=3.6\right.$ to $\left.4.3 \mathrm{~ms}\right)$. Biotin-filled MNTB neurons revealed one to two small caliber primary dendrites (Scott et al., 2005).

Here we calculated $R_{m}$ using first current-clamp recordings from mouse MNTB neurons. Figure 3A shows recordings from a P20 mouse MNTB principal cell at room temperature. Cells were held at a resting membrane potential of $-70 \mathrm{mV}$. Depolarizing step current injections of $150 \mathrm{pA}$ elicited one action potential spike and outward rectification, consistent with previous reports (Banks and Smith, 1992; Forsythe and Barnes-Davies, 1993; Wang et al., 1998). The spike threshold was about $-45 \mathrm{mV}$. The IV curve was generated using $200 \mathrm{~ms}$ current pulses from $-300 \mathrm{pA}$ to $+150 \mathrm{pA}$ relative to the holding current. The pulses were applied in $50 \mathrm{pA}$ steps with $3 \mathrm{~s}$ inter pulse interval. The IV curve were built with values obtained from the peak of the hyperpolarizing sag (black dots) and the mean of the last $10 \mathrm{~ms}$ (open triangle; Figure 3A). The average IV curve was linear (ohmic; dashed line) over a range of negative current with a slope (input resistance) $R_{m}=207 \mathrm{M} \Omega$ (Figure 3B). Deviations from linearity are due to activation of $\mathrm{I}_{\mathrm{KLT}}$ for positive currents and $\mathrm{I}_{\mathrm{h}}$ for negative currents (Brew and Forsythe, 1995; MacLeod and Carr, 2012). For small current injections, the average $R_{m}=247 \pm 65 M \Omega(n=6$; P20). This was not significantly different from P28 neurons: $R_{m}=200 \pm 21 \mathrm{M} \Omega\left(n=4 ; P 28 ; 24^{\circ} \mathrm{C}\right)$. This was however substantially larger than $\mathrm{R}_{\mathrm{m}}$ for P20 gerbils (Scott et al., 2005) or 3-5 week old rats (Banks and Smith, 1992). We attribute this difference, in part, to the smaller size of mouse MNTB neurons, compared to gerbil or rat neurons, and to room temperature (see Figure 3E).

We found that a short 2-ms current injection elicits a voltage transient that decays as a doubleexponential function (Figure 3C). The fast $\left(\tau_{\mathrm{f}}\right)$ and slow $\left(\tau_{\mathrm{s}}\right)$ components of the membrane time constant $\left(\tau_{\mathrm{m}}\right)$ were unchanged for different depolarizing steps $(50 \mathrm{pA}: 1.6 \pm 0.5$ and $6.5 \pm 0.7 \mathrm{~ms} ; 150 \mathrm{pA}: 1.3 \pm 0.4$ and $6.3 \pm 0.7 \mathrm{~ms}$ for $\tau_{\mathrm{f}}$ and $\tau_{\mathrm{s}}$, respectively; $\mathrm{n}=4$; Figure 3C). This double-exponential decay of the EPSP suggests that the MNTB cell cannot be modeled as a passive isopotential spherical cell or point-neuron, which would have only a single exponential decay with $\tau_{M}=C_{m} R_{m}$ (Golding, 2012). If we assume a "stick-andball" passive neuron model the voltage $\mathrm{V}(\mathrm{t})$ as a function of time should decay according to the Rall function (Rall, 1969):

$$
V(t)=V_{0}+A *\left[1-\operatorname{erf}\left(\sqrt{t / \tau_{M}}\right)\right]
$$

where $\mathrm{V}_{0}$ and $\mathrm{A}$ are constants and $\operatorname{erf}(\mathrm{x})$ is the error function:

$$
\operatorname{erf}(x)=\frac{2}{\sqrt{\pi}} \int_{0}^{x} e^{-y^{2}} d y
$$

The best fit values for $\tau_{M}$ are $6.4 \pm 0.7 \mathrm{~ms}(\mathrm{n}=6)$ and $7.8 \pm 0.8 \mathrm{~ms}(\mathrm{n}=5)$ for 50 and $150 \mathrm{pA}$ current pulses respectively, which are not significantly different (unpaired Student t test; $p>0.05$ ). As shown in Figure 3C both a double exponential function and a Rall function provide excellent fits to the data. 
Figure 3D shows current clamp responses of more mature neurons (P28) at more physiological temperatures $\left(35^{\circ} \mathrm{C}\right)$. To elicit an AP spike larger step current injections are now required than for room temperature. This is due to a significant reduction in the input resistance of the neurons at high temperature (for the same P28 neurons: $R_{m}=200 \pm 21 \mathrm{M} \Omega$ at $24^{\circ} \mathrm{C}$ and $\mathrm{R}_{\mathrm{m}}=119 \pm 19 \mathrm{M} \Omega$ at $35^{\circ} \mathrm{C} ; \mathrm{n}=4 ; \mathrm{p}=0.0002$ paired Students t-test; Figure 3E). Current injection in the soma of a nonisopotential neuron leads to current flow between different compartments and $\mathrm{V}(\mathrm{t})$ can be expressed as the sum of exponential functions (Rall, 1969; Major et al., 1993). Figure 3F shows voltage responses of a P28 neuron to small hyperpolarizing pulses (-50 pA step) for two temperatures. The responses again require a double exponential fit with both fast $\left(\tau_{\mathrm{f}}\right)$ and slow $\left(\tau_{\mathrm{s}}\right)$ time constants. The value of $\tau_{\mathrm{s}}=\tau_{\mathrm{M}}$ (the membrane time constant) and $\tau_{\mathrm{f}}$ is related to the dendrites and axon (Rall, 1969). The electrotonic length is $L=$ $\pi / \sqrt{\left(\tau_{s} / \tau_{f}-1\right)}=1.6$ for P20 and P28 MNTB neurons at $24^{\circ} \mathrm{C}(\mathrm{n}=4$; Rall, 1969), which is larger than values for hippocampal neurons $(L=0.9$; Brown et al., 1981), which have thicker dendrites $(9-10 \mu \mathrm{m})$. The total membrane capacitance can be calculated using $C_{m}=\tau_{s} / R_{0}$, where $R_{0}$ is the input resistance times the percentage of the amplitude of the slow component (59 $\pm 5 \%$; $n=6$; see Golowasch et al., 2009; Major et al., 1993). The average $C_{m}$ calculated in this manner is $45.0 \pm 4.5 \mathrm{pF}\left(\mathrm{n}=6\right.$ for $\left.24^{\circ} \mathrm{C}\right)$.

\section{Developmental changes in passive membrane properties of MNTB neurons}

Capacitive currents from passive and multi-compartment neurons can be used to estimate the $\mathrm{C}_{\mathrm{m}}$ of the different compartments under voltage clamp (Mejia-Gervacio et al., 2007; Nadeau and Lester, 2000 and 2002). This analysis reveals three main compartments: soma, axon and dendrites. To better correlate changes in neuronal compartments with our estimates of $\mathrm{C}_{\mathrm{m}}$ we performed measurements at four different age groups (P5-6, P9-11, P15-17 and P21-24). Capacitive currents were measured in response to $-10 \mathrm{mV}$ hyperpolarizing voltage steps, immediately after break in, with minimum filtering. The decay time course of the capacitive current was fit with exponential functions. In the youngest group (P5-6), capacitive current transients were well-fitted with the sum of two exponential components which we shall refer to as the fast and medium components, respectively (Table 2). Likewise, in P9-11 animals, 87\% of MNTB neurons exhibited two exponential decay components and 10\% exhibited a single component. However, the remaining 3\% exhibited a third, much slower component. In the oldest group (P21-24) the percentage of neurons with a tri-exponential decay increased significantly to $46 \%$ (Figure 4). In addition, the steady-state input resistance $\left(\mathrm{R}_{\mathrm{I}}\right)$ significantly dropped during post-natal development, from 0.8 $\pm 0.1 \mathrm{G} \Omega$ at $\mathrm{P} 5-6(\mathrm{n}=5)$ to $0.6 \pm 0.06 \mathrm{G} \Omega$ at P9-11 $(\mathrm{n}=26)$ and then to $0.2 \pm 0.03 \mathrm{G} \Omega$ for $\mathrm{P} 21-24$ neurons $(\mathrm{n}=16 ; \mathrm{p}=0.0002)$ with triexponential decay. Steady-state input resistance in P21-24 neurons with bi-exponential decay was higher: $0.5 \pm 0.09 \mathrm{G} \Omega(\mathrm{n}=19)$. Membrane input resistances at $24^{\circ} \mathrm{C}$ were similar when we performed voltage and current clamp recordings in the same group of cells (P20: $246 \pm 60$ and $250 \pm 70 \mathrm{M} \Omega$, respectively; $\mathrm{n}=6$ ). We conclude that during the first three weeks the passive properties of mouse MNTB neurons undergo substantial changes, but are not significantly different from P20 to P28. 
From Table 2 we see that the estimated $C_{m}$ values for the P21-24 group of cells with three compartments are $\mathrm{C}_{\mathrm{f}}=9 \mathrm{pF}$ and $\mathrm{C}_{\mathrm{med}}=12 \mathrm{pF}$ and $\mathrm{C}_{\mathrm{s}}=18 \mathrm{pF}$, so that the total $\mathrm{C}_{\mathrm{m}}=39 \mathrm{pF}$. This is close to the estimates obtained with current clamp (45 pF; Fig. 3E) and SBEM (Table 1). However, do the three separate values of $\mathrm{C}_{\mathrm{f}}, \mathrm{C}_{\text {med }}$ and $\mathrm{C}_{\mathrm{s}}$ reflect the three distinct compartments of cell soma, dendrites and/or axon?

\section{Developmental changes in dendritic length}

To determine the relationship between developmental changes in morphology and passive membrane properties we performed confocal reconstructions of MNTB neurons filled through the patch pipette with Alexa 555 dye (Figure 5). The size of the soma was measured as the geometric mean of major and minor axes and did not change significantly $(16 \pm 1.2 \mu \mathrm{m}$ at P9-11 vs. $17 \pm 1.6 \mu \mathrm{m}$ at P21-24). Likewise, the length of the axon (measured by tracing in the confocal field of views) within the brainstem slices was not significantly different for the two age groups (172 $\pm 13 \mu \mathrm{m}$ vs $203 \pm 25 \mu \mathrm{m})$. At P9-11, MNTB neurons exhibited one or two very small dendritic stubs with an average length of $31 \pm 10 \mu \mathrm{m}$ as shown in Figure $\mathbf{5 A}$ (see also Sätzler et al., 2002). By P21-24, the dendrites had grown significantly to $80 \pm 17 \mu \mathrm{m}$ ( $\mathrm{p}=0.03$; Figure 5B) and often bifurcated. We conclude that the major morphological difference likely to explain the changes in passive neuronal properties is the elaboration of dendritic structures that increase 2.6-fold in length between P9-11 and P21-24 as summarized in Figure 5C.

\section{Membrane compartments and passive cell properties}

We occasionally observed neurons with mono-exponential decay of their capacitive transients (4 of 44 cells at P9-17). Imaging showed that these neurons lacked both dendrites and axon, presumably lost during the brain slicing procedure. Figure 6A shows a cell exhibiting a mono-exponential decay. In such cells, the time constant was $0.2 \pm 0.03 \mathrm{~ms}(\mathrm{n}=4)$, a value very similar to the fast component of decay in intact cells $(\mathrm{p}=0.23$; Fig. 4B). The integral of the capacitive current divided by the voltage step gives the associated capacitance which was $14.0 \pm 1.7 \mathrm{pF}$. Of all neurons tested, the mono-exponential decay group had the highest input resistance $(0.9 \pm 0.1 \mathrm{G} \Omega$; Figure $6 \mathrm{D} \&$ Table 2$)$, indicating that the axon and dendrites make substantial contributions to input conductance. Somata of the MNTB neuron were ellipsoid. Based on the measurements of major and minor axis, the surface area of MNTB neurons is about $970 \mu \mathrm{m}^{2}$ and the predicted membrane capacitance (assuming a smooth surface as demonstrated by EM; Fig. 1 ) is $9.7 \pm 1.7$ $\mathrm{pF}(\mathrm{n}=4)$. This value is similar to the value which we obtained by fitting the capacitive current decay by using the formula: $\tau_{\mathrm{f}} \times \mathrm{A}_{\mathrm{f}} / 10 \mathrm{mV}(9.0 \pm 0.6 \mathrm{pF}, \mathrm{n}=4$; Fig. 6D). The somewhat larger value obtained by integrating the capacitance transient presumably reflects contributions from axon or dendrite stubs. We conclude that the fastest component of capacitive current decay largely reflects charging of the soma and proximal portions of the axon or dendrite. As mentioned above, neurons lacking processes $(n=4)$ had a large $\mathrm{R}_{\mathrm{I}}$ of about $0.9 \pm 0.1 \mathrm{G} \Omega$. This value was higher than neurons with an axon $(0.54 \pm 0.05 \mathrm{G} \Omega$; $\mathrm{n}=55)$ or additional dendrites $(0.2 \pm 0.02 \mathrm{G} \Omega ; \mathrm{n}=20)$. Thus, adding compartments increases the cellular surface area, 
and presumably leak channels, which in turn decreased the $\mathrm{R}_{\mathrm{I}}$. The calculated access (series) resistance (from $\tau=\mathrm{C}_{\mathrm{m}} \times \mathrm{R}_{\mathrm{a}}$ ) was $14.3 \mathrm{M} \Omega$, in good agreement with the estimate from the patch clamp amplifier.

Given these results with single compartment cells, which lack axons and dendrites, we suggest that $\mathrm{C}_{\mathrm{f}}$ values reflect mostly the soma. The P9-11 cells with two components suggest that that $\mathrm{C}_{\text {med }}$ reflects mostly the lightly myelinated axon. Thus, for cells with three compartments, $\mathrm{C}_{\mathrm{s}}$ may reflect mostly the dendrites. However, there is some uncertainty on how much one can separate axon and dendritic capacitance with these methods given that they have similar calibers initially as they leave the soma (1.5 $\mu \mathrm{m}$ for dendrites and $\sim 1.0 \mu \mathrm{m}$ for the myelinated axon). However, at P21-24 myelin will greatly reduce the axonal capacitance so it may have very little contribution to the overall $\mathrm{C}_{\mathrm{m}}$ of the MNTB cell. We thus propose that for the P21-24 group of MNTB cells with three compartments the $\mathrm{C}_{\mathrm{f}}=9 \mathrm{pF}$ reflects mostly the soma, but $\mathrm{C}_{\mathrm{med}}=12 \mathrm{pF}$ and $\mathrm{C}_{\mathrm{s}}=18 \mathrm{pF}$ (Figure 4D and Table 2), probably reflect the 2 to 3 long and thin dendrites and to some unknown degree the axon.

\section{Influence of dendrites on signal transfer: EPSCs and EPSPs}

Developmental changes in EPSC time course also affect the time course of the EPSP (Joshi and Wang, 2002; Taschenberger and von Gersdorff, 2000). In addition, an increase in potassium and $\mathrm{I}_{\mathrm{h}}$ currents during development can also change the EPSP time course (Golding, 2012; Leão et al., 2010). To determine the relative importance of these factors, we measured EPSCs and EPSPs from the principal cells of the MNTB during afferent fiber stimulation. Typical examples (average of 5 sweeps at $0.1 \mathrm{~Hz}$ ) are shown in Figure 7A and 7B. Postsynaptic action potentials were blocked by QX-314 in the patch pipette solution. EPSCs from P9-11 synapses exhibited a bi-exponential decay with time constants of $1.0 \pm 0.1 \mathrm{~ms}$ (92\% of current amplitude) and $7.8 \pm 0.6 \mathrm{~ms}(\mathrm{n}=14$; Fig. 7C). At P21-24, EPSC decay was mono-exponential with a fast time constant of $0.5 \pm 0.07 \mathrm{~ms}(\mathrm{n}=8)$. The very fast kinetics of the EPSCs means that the voltage response is predicted to be determined largely by the passive membrane time constant $\left(\tau_{\mathrm{M}} \sim 6-7 \mathrm{~ms}\right.$ at $\mathrm{P} 20$ for $24^{\circ} \mathrm{C}$; Fig. 3). Indeed, EPSPs from P9-11 neurons exhibited a bi-exponential decay with time constants of $5.5 \pm$ $1.2 \mathrm{~ms}$ (64\% of decay) and $31.0 \pm 4.7 \mathrm{~ms}\left(\mathrm{n}=8\right.$; Fig. 7D), and a weighted time constant $\tau_{\mathrm{wd}}=14.7 \mathrm{~ms}(\mathrm{see}$ Methods). By contrast, the EPSP decay at P21-24 was a bi-exponential function with much faster decay kinetics of $1.8 \pm 0.5 \mathrm{~ms}$ (96\% of decay) and $8.0 \pm 2.23 \mathrm{~ms}(\mathrm{n}=6)$, and thus $\tau_{\mathrm{wd}}=2.1 \mathrm{~ms}$.

To examine the importance of voltage activated currents in a more functional context, we examined the decay time constants of large EPSCs and EPSPs generated at low frequency (Fig. 7) and the depressed EPSCs and EPSPs recorded at the end of a $100 \mathrm{~Hz}$ train of afferent fiber stimulation (Figure 8; see also Taschenberger and von Gersdorff, 2000). The slow decay of the last EPSC in Figure 8Ai may be due to glutamate pooling in the synaptic cleft of the P11 calyx synapse and a lower expression of glutamate transporters (Renden et al., 2005), whereas the faster decay of the last EPSC at P23 (Figure 8Bi) may be due to the fenestration of the calyx terminal into long finger-like stalks and swellings (Rowland et al., 2000). 
Figure 8Aii shows EPSPs obtained with QX-314 in the patch pipette to block $\mathrm{Na}^{+}$currents and AP spikes. At P11 a large depolarizing plateau is produced by the EPSP train. This is due to the summation of the slowly decaying EPSPs and activation of NMDA receptors (Taschenberger and von Gersdorff, 2000). At P23, after blocking postsynaptic APs, the fast decaying EPSPs do not summate (Figure 8Bii). These data indicated a slower decay of the small depressed EPSPs recorded at the end of the train compared to the single EPSPs shown in Figure 7. Similar results were observed in 4 recordings at P911 and 4 at P21-24. The dramatic differences shown here illustrate the importance of rapid EPSC decay and short membrane time constant for a rapid EPSP decay.

We also next determined whether the weighted time constant of EPSCs and EPSPs were correlated with the membrane resting input resistance $\left(\mathrm{R}_{\mathrm{I}}\right)$. Figure 9A shows the relationship between the weighted decay time constants of EPSCs with respect to $\mathrm{R}_{\mathrm{I}}$. The weighted decay time constant of the EPSCs in younger (P9-11; $n=12)$ and older (P21-24; $n=9)$ MNTB neurons did not correlate with $\mathrm{R}_{\mathrm{I}}(\mathrm{r}=0.10$ for P9-11 and r=0.001 for P21-24 neurons). By contrast, the weighted decay time constant of the EPSPs showed a positive correlation with $\mathrm{R}_{\mathrm{I}}$ (Fig. 9B). Moreover, P21-24 neurons displayed a steeper slope and exhibited a strong linear correlation ( $\mathrm{r}=0.46$ for $\mathrm{P} 9-11$ and $\mathrm{r}=0.82$ for $\mathrm{P} 21-24$ neurons). We conclude that the observed changes in membrane passive properties during development have important consequences for the time course of EPSPs in MNTB neurons.

\section{Dendrites accelerate the EPSP decay}

To further examine the correlation between the capacitive currents, $\mathrm{R}_{\mathrm{I}}$, dendrites, and their synaptic currents and potentials, we examined the fraction of older neurons (P21-24; $\mathrm{n}=5)$ which displayed bi-exponential capacitive current. The morphology of these cells showed a prominent soma and a long axon, but little or no dendrites (perhaps lost during slicing; Figure 10A). For these cells, the decay time constants of the capacitive currents were $\tau_{\mathrm{f}}(0.15 \pm 0.02 \mathrm{~ms})$ and $\tau_{\mathrm{m}}(1.9 \pm 0.18 \mathrm{~ms})$. These cells had a relatively large $\mathrm{R}_{\mathrm{I}}=0.55$ $\pm 0.12 \mathrm{G} \Omega$. We also checked the decay time constants of both the EPSCs and the EPSPs of these neurons. The weighted decay time constant of the EPSCs and EPSPs were $0.8 \pm 0.3 \mathrm{~ms}$ and $9.84 \pm 1.4 \mathrm{~ms}$, respectively. We next compared these neurons which lacked dendrites (P21-24; $\mathrm{n}=5)$ to neurons with dendrites (P21-24; $\mathrm{n}=5)$. The weighted decay time constant of EPSC in neurons with dendrites was $0.5 \pm 0.03 \mathrm{~ms}$ which was not different from neurons without dendrites $(\mathrm{p}=0.21$; Fig. $8 \mathrm{~B})$. However, the weighted EPSP decay time constant of neurons with dendrites was significantly faster ( $\tau_{\mathrm{wd}}=1.85 \pm 0.33 \mathrm{~ms}$; $\mathrm{p}=0.0005$; Fig. 10B). Thus, P21-24 neurons with dendrites and triphasic capacitive current decay have a 5fold faster EPSP decay compared to neurons lacking dendrites and showing bi-phasic capacitive current decay (Fig. 10C). In fact, P21-24 neurons without dendrites had passive membrane properties and EPSP kinetics more similar to P9-11 neurons. We therefore suggest that it is the presence of dendrites that causes the major observed developmental changes in MNTB membrane properties and the fast decay of the EPSP.

\section{Computer modeling of EPSPs and leaky dendrites}


In order to synthesize and interpret our data from voltage and current clamp measurements we generated a compartmental model of an MNTB neuron. For a point neuron (or a single and uniform spherical compartment), the membrane time constant is given by $\tau_{\mathrm{m}}=\mathrm{C}_{\mathrm{m}} / \mathrm{G}_{\mathrm{m}}$, the ratio of membrane capacitance (in $\mathrm{F} / \mathrm{cm}^{2}$ ) to resting leak conductance (in $\mathrm{S} / \mathrm{cm}^{2}$ ). Thus, increasing the total membrane area will not change the membrane time constant. As an example, a point-neuron model with a standard $\mathrm{C}_{\mathrm{m}}=10 \mathrm{fF} / \mu \mathrm{m}^{2}=1 \mu \mathrm{F} / \mathrm{cm}^{2}$ and $\mathrm{G}_{\mathrm{m}}=200 \mu \mathrm{S} / \mathrm{cm}^{2}$ has a single exponential time constant $\tau_{\mathrm{m}}=5 \mathrm{~ms}$ and a synaptic current $\mathrm{I}=5 \mathrm{nA}$ generates a peak EPSP amplitude of $10 \mathrm{mV}$, if the resting membrane conductance is $\mathrm{g}_{\mathrm{m}}=0.5 \mu \mathrm{S}\left(\mathrm{V}_{\mathrm{m}}=\right.$ $\mathrm{I} / \mathrm{g}_{\mathrm{m}}$; see Golding, 2012).

How does EPSP decay change after an increase in dendrite length and dendritic conductance in a non-point neuron? To gain further insights on the role of dendritic length and leak conductance on EPSP decay, we generated passive compartmental MNTB cell models that consisted of a single dendrite of various lengths, a soma and a thin axon (Figure 11). We applied single EPSPs to the soma based on the model of Graham et al (2001) and Leão et al. (2008). Modeling parameters and decay values are listed in Table 3. EPSPs decays were fit with double exponentials. When the cell was implemented with a $10 \mu \mathrm{m}$ long dendrite and a leak conductance $\left(g_{L}\right)$ of $62.5 \mu \mathrm{S} / \mathrm{cm}^{2}$, the weighted decay time constant was $11.6 \mathrm{~ms}$ (Figure 11Ai). After increasing $g_{L}$ to $500 \mu \mathrm{S} / \mathrm{cm}^{2}$, maintaining the dendrite length equal to $10 \mu \mathrm{m}$, the EPSP weighted decay time-constant was $9.7 \mathrm{~ms}$, Using an $80 \mu \mathrm{m}$-dendrite, the weighted decay time was 11 $\mathrm{ms}$ for $g_{L}=62.5 \mu \mathrm{S} / \mathrm{cm}^{2}$ and $6.5 \mathrm{~ms}$ for $g_{L}=500 \mu \mathrm{S} / \mathrm{cm}^{2}$ (Figure 11Aiv). Figure $11 B$ shows that without dendrites the EPSP decays more like a single exponential and does not match the clear double exponential decay we observed in Figure 3C with short current injections. Figure 11C shows the expected result that just adding longer dendrites with a constant total conductance $g_{L}=250 \mu \mathrm{S} / \mathrm{cm}^{2}$ does not change EPSP decay kinetics. Thus, cells with longer dendrites that increase the leak conductance produce faster doubleexponential decay kinetics for simulated EPSPs.

Note that EPSP amplitudes are normalized in Figure 11 to better compare the EPSP decay. Of course, a large leak conductance, mediated for example by low threshold $\mathrm{K}^{+}$channels, will also decrease the amplitude of the EPSP because $\mathrm{V}_{\mathrm{m}}=\mathrm{I} / \mathrm{g}_{\mathrm{m}}$ (Golding, 2012). Thus, if a large leak conductances are necessary to produce a fast EPSP decay, a large EPSC is also necessary to maintain a super-threshold EPSP amplitude. We conclude that an increase in leak conductance will decrease membrane time constant and will speed up EPSPs provided the membrane time constant is slower than the synaptic conductance. This is indeed the case for the very fast and large AMPA-receptor-mediated EPSC of the calyx of Held synapse.

\section{Discussion ( $1482<1500$ words)}

Our results show that the principal neurons of the MNTB undergo dramatic morphological changes during the first three postnatal weeks. The raison de être for the development of long and thin dendrites in MNTB neurons has remined mysterious given that the major excitatory input resides in the soma. In order to assess 
the contribution of dendritic properties in shaping the evoked EPSP kinetics, we studied the MNTB neurons with and without dendrites, which were presumably severed during the slicing procedure. We found that EPSP decay was faster in older neurons that had longer dendrites and a decreased input resistance. Dendrites may thus play an important role in determining the synaptic integration of auditory signals in the MNTB.

\section{MNTB neurons have long and thin dendrites}

Dendrites are the main sites of synaptic input for most neurons and they play both active and passive roles in synaptic integration. While MNTB neurons receive both excitatory and inhibitory synaptic inputs onto the soma, the presence of functional dendritic inputs is not clear (Smith et al., 1998; Hamann et al., 2003; Leao et al., 2004). Electron microscopic studies describe some non-calyceal small bouton type terminals on the cell body and dendrites (Lenn and Reese, 1966; Elezgarai et al., 2003). Anatomical evidence also suggests that the calyx of Held can make occasional contact with proximal dendrites (Morest, 1973; Rowland et al., 2000). The dendrites of MNTB neurons are also enriched with $\mathrm{Na}^{+}$and $\mathrm{K}^{+}$channels, which probably play a major role in promoting and adapting the firing pattern of the MNTB cell (Perney and Kaczmarek, 1997; Elezgarai et al., 2003; Leão et al., 2008).

Our SBEM results reveal that P30 mouse MNTB cells have 1 to 3 thin dendrites (diameter $~ 1.5$ microns). The dendrites bifurcated into 2-3 thin branches and spanned an overall distance of about 80 to 200 microns. They receive sparse synaptic bouton input (Figure 2). Our confocal imaging with Alexa dye revealed that P21-24 MNTB neurons also have similar thin and long dendrites that extended for 80 microns. However, P9-11 neurons had 1 or 2 shorter dendrites that extended for only about 25 microns. The overall morphology of the P21-24 cells was very similar to the morphology revealed by SBEM for the P30 cells. Indeed, our patch clamp recordings reveal an overall $\mathrm{C}_{\mathrm{m}}$ of about $39 \mathrm{pF}$ for P21-24 cells, whereas the total surface area of the P30 cells measured with SBEM is equivalent to about 33 to $41 \mathrm{pF}$, depending on various assumptions of cell shrinkage due to fixation and the membrane specific capacitance.

\section{Passive properties change during development}

The majority of the younger neurons (P9-11) displayed biexponential capacitive current decay, whereas a major subset of more adult-like (>P21) neurons showed an additional third component. During the same time period, the input resistance declined with development (from about $0.43 \pm 0.04 \mathrm{G} \Omega$ at $\mathrm{P} 11$ to $0.20 \pm 0.02$ $\mathrm{G} \Omega$ at $\mathrm{P} 23 ; \mathrm{p}=0.003$ ). The amount of current needed to elicit a single action potential increased during development (from $175 \pm 9$ pA for P11 to $200 \pm 24$ pA for P23; p=0.048). After measuring their passive properties, the neurons were imaged with confocal microscopy and the dendritic length was observed to double after mouse pup weaning (>P21) compared to young immature animals ( P9-11; pre-hearing), whereas the mean diameter of the soma and the axonal length remained constant (see Figure 4 and 5). This 
correlation of physiological properties and imaging suggests that the additional third capacitive current component observed during development may reflect the longer dendrites in older neurons.

\section{Why locate "leak" current and $\mathrm{Na}^{+}$and $\mathrm{K}^{+}$channels on long and thin dendrites?}

Several different potassium channels are located on MNTB principal cells (Berntson and Walmsley, 2008; Brew and Forsythe 1995; Johnston et al., 2010). An action potential in the calyx of Held triggers glutamate release onto the soma of the MNTB principal cell. This generates a brief and large inward current that rapidly depolarizes the soma producing a fast rising EPSP that rapidly depolarizes the axon initial segment (AIS), which has a high density of $\mathrm{Na}^{+}$channels (Leão et al., 2005). The depolarization then opens low threshold $\mathrm{K}_{\mathrm{v}} 1.1 / 1.2$ potassium channels in the AIS and high threshold $\mathrm{K}_{\mathrm{v}} 3.1$ potassium channels in the soma, dendrites and AIS (Johnston et al., 2010). Interestingly, $\mathrm{K}_{\mathrm{v}} 3.1 \mathrm{~b}$ is strongly concentrated in the dendrites of P16 and adult rat MNTB cells (Elezgahrai et al., 2003). This large $\mathrm{I}_{\mathrm{K}}$ current quickly hyperpolarizes the soma back to resting membrane potentials via an outward flux of $\mathrm{K}^{+}$ions. However, if these $\mathrm{K}_{\mathrm{v}}$ channels were concentrated in the synaptic cleft or near the calyx of Held they may accumulate and depolarize the calyx membrane potential. This may be deleterious for a well-timed release of glutamate. Thus, localizing $\mathrm{K}_{\mathrm{v}}$ channels to the dendrites and AIS may place them at a safe distance from the calyx, where they can produce a large $\mathrm{I}_{\mathrm{K}}$ that does not influence the high frequency firing of the calyx nerve terminal. Indeed, $\mathrm{K}_{\mathrm{v}} 3.1 \mathrm{~b}$ potassium channels are excluded from the synaptic cleft of the calyx of Held (Elezgahai et al. 2003).

MNTB neurons have a low density of $\mathrm{Na}^{+}$channels in their soma (Leão et al., 2005). We speculate that excluding $\mathrm{Na}^{+}$channels from the soma and synaptic cleft avoids a potential reduction in the $\mathrm{Na}^{+}$ion concentration in the narrow synaptic cleft, which has a narrow $20 \mathrm{~nm}$ width and where AMPA receptors are located. Importantly, a low density of somatic $\mathrm{Na}^{+}$channels has also been observed at other auditory brainstem neurons, where it allows the EPSP to have a faster decay (Yang et al., 2016). Surprisingly, the dendrites of the MNTB cell have a high density of $\mathrm{Na}^{+}$channels (Leão et al., 2008). These may boost the EPSP amplitude, but also slow its decay (Leão et al., 2008; Yang et al., 2016; Ceballos et al., 2017). Moreover, MNTB neurons also have Slick and Slack $\mathrm{Na}^{+}$-dependent $\mathrm{K}^{+}$channels that regulate their highfrequency firing (Yang et al., 2007; Brown and Kaczmarek, 2011). If these $\mathrm{K}^{+}$channels are located in the dendrite, next to $\mathrm{Na}^{+}$channels, they also may play a critical role in speeding up the EPSP decay.

\section{Firing spikes at high rates in the AIS}

The large depolarization of the somatic EPSC produces a rapid opening of $\mathrm{Na}^{+}$channels in the long (10 to 15 micron) and thin unmyelinated axon initial segment (AIS; see Figure 1B), which has a high density of $\mathrm{Na}^{+}$channels (Leão et al., 2005). Our SBEM reveals that the $\mathrm{C}_{\mathrm{m}}$ of the AIS is only $1.1 \mathrm{pF}$. A large EPSP can thus quickly bring this small area to threshold with the opening of relatively few Na channels. A combination of local $\mathrm{I}_{\mathrm{KLT}}$ and $\mathrm{I}_{\mathrm{KHT}}\left(\mathrm{K}_{\mathrm{v}} 3.1\right)$ type channels then produces a rapid outward flux of $\mathrm{K}^{+}$ions that 
quickly brings the membrane potential back to resting levels. The high density of Na channels present in the AIS allows for a large surplus of available Na channels for high frequency firing (Madeja, 2000). This large surplus allows the postsynaptic MNTB cell to fire spikes at rates as high as $800 \mathrm{~Hz}$ for extended periods of time (Taschenberger and von Gersdorff, 2000).

\section{Computer modeling: Leaky dendrites speed up the EPSP decay}

The role of the dendrite in determining integrative properties of MNTB cells was further investigated by a simple computational model of a passive neuron. Our model consisted of a soma, axon and dendrites of various lengths (or devoid of dendrite) and various levels of leakage conductance. The simulations demonstrate that dendrites in MNTB neurons can minimize temporal summation of synaptic currents by shortening the decay of EPSPs. A longer dendrite augments considerably the membrane area and overall $\mathrm{C}_{\mathrm{m}}$, which would slow EPSP decay if it had a small or no leak conductance. However, they also serve as extra remote sites for locating leak potassium channels or low threshold potassium channels. Hence, the dendrite can serve as a sink for the calyceal EPSPs generated at the soma, accelerating the decay of the EPSP. Our model also showed that the dendritic effect on EPSP decay is mostly attributed by the lowering of input resistance rather than changes in surface area (or capacitance) due to longer dendrites.

Our main experimental observation is that MNTB neurons that lack dendrites have a slower decay of the EPSP (Figure 10C). These results uncovered a dendrite-mediated speeding for the EPSPs for more mature MNTB neurons that is analogous to what has been proposed for interneuron axons in the cerebellum (axonal speeding) by Mejia-Gervacio et al. (2007). These authors observed a slower decay of the EPSP when they cut the interneuron axon with a laser. Our computer simulations also suggest that longer dendrites with a larger leak conductance produce faster EPSP decay kinetics (Figure 11). In summary, our results suggest that the thin and long dendrites of MNTB neurons provide a fast current sink that accelerates synaptic potentials. This reduces EPSP summation during long trains of repetitive high frequency afferent fiber stimulation.

\section{References}

Banks MI, Smith PH (1992) Intracellular recordings from neurobiotin-labeled cells in brain slices of the rat medial nucleus of the trapezoid body. J Neurosci 12:2819-2837.

Bekkers JM, Häusser M (2007) Targeted dendrotomy reveals active and passive contributions of the dendritic tree to synaptic integration and neuronal output. PNAS 104: 11447-11452.

Berntson AK, Walmsley B (2008) Characterization of a potassium-based leak conductance in the medial nucleus of the trapezoid body. Hear Res 244:98-106.

Brew HM, Forsythe ID (1995) Two voltage-dependent $\mathrm{K}^{+}$conductances with complementary functions in postsynaptic integration at a central auditory synapse. J Neurosci 15:8011-8022. 
Brown MR, Kaczmarek LK (2011) Potassium channel modulation and auditory processing. Hear Res 279:32-42.

Brown TH, Fricke RA, Perkel DH (1981) Passive electrical constants in three classes of hippocampal neurons. J Neurophysiol 4:812-827.

Ceballos CC, Roque AC, Leão RM (2017) The role of negative conductances in neuronal subthreshold properties and synaptic integration. Biophys Rev. 9:827-834.

Elezgarai I, Diez J, Puente N, Azkue JJ, Benitez R, Bilbao A, Knopfel T, Donate-Oliver F, Grandes P (2003) Subcellular localization of the voltage-dependent potassium channel Kv3.1b in postnatal and adult rat medial nucleus of the trapezoid body. Neuroscience 118:889-898.

Fekete A, Nakamura Y, Yang Y-M, Herlitze S, Mark MD, DiGregorio DA, Yang L-Y (2019) Underpinning heterogeneity in synaptic transmission by presynaptic ensembles of distinct morphological modules. Nat Commun 10:826.

Forsythe ID, Barnes-Davies M (1993) The binaural auditory pathway: membrane currents limiting multiple action potential generation in the rat medial nucleus of the trapezoid body. Proc Biol Sci 251:143-150.

Geiger JR, Lübke J, Roth A, Frotscher M, Jonas P (1997) Submillisecond AMPA receptor-mediated signaling at a principal neuron-interneuron synapse. Neuron 18:1009-1023.

Gentet LJ, Stuart GJ, Clements JD (2000) Direct measurement of specific membrane capacitance in neurons. Biophys J 79:314-320.

Golding (2012) Neuronal response properties and voltage-gated ion channels in the auditory system. Synaptic mechanisms in the auditory system. Springer Handbook of Auditory Research. Vol. 41 Editors: Trussell, L.O., Popper, A.N., and Fay, R.R.

Golding NL, Robertson D, Oertel D (1995) Recordings from slices indicate that octopus cells of the cochlear nucleus detect coincident firing of the auditory nerve fibers with temporal precision. J Neurosci 15:3138-3153.

Golowasch J, Thomas G, Taylor AI, Patel A, Pineda A, Khalil C, Nadim F (2009) Membrane capacitance measurements revisited: Dependence of capacitance value on measurement method in nonisopotential neurons. J Neurophysiol 102:2161-2175.

Graham BP (2001) Pattern recognition in a compartmental model of a CA1 pyramidal neuron. Network 12:473-492.

Gulledge AT, Kampa BM, Stuart GJ (2005) Synaptic integration in dendritic trees. J Neurobiol 64:75-90.

Hamann M, Billups B, Forsythe ID (2003) Non-calyceal excitatory inputs mediate low fidelity synaptic transmission in rat auditory brainstem slices. Eur J Neurosci 18:2899-2902.

Hennig MH, Postlethwaite M, Forsythe ID, Graham BP (2007) A biophysical model of short-term plasticity at the calyx of Held. Neurocomputing 70:1626-1629.

Hines ML, Carnevale NT (2001) NEURON: a tool for neuroscientists. Neuroscientist 7:123-135.

Hoffpauir BK, Grimes JL, Mathers PH, Spirou GA (2006) Synaptogenesis of the calyx of Held: rapid onset of function and one-to-one morphological innervation. J Neurosci 26:5511-5523.

Johnston J, Forsythe ID, Kopp-Scheinflug C (2010) Going native: voltage-gated potassium channels controlling neuronal excitability. J Physiol 588:3187-3200. 
Joshi I and Wang LY (2002) Developmental profiles of glutamate receptors and synaptic transmission at a single synapse in the mouse auditory brainstem. J Physiol 540:861-873.

Kandler K, Friauf E (1993) Pre- and postnatal development of efferent connections of the cochlear nucleus in the rat. J Comp Neurol 328:161-184.

Kopp-Scheinpflug C, Steinert JR, Forsythe ID (2011) Modulation and control of synaptic transmission across the MNTB. Hear Res 279:22-31.

Kuba H, Yamada R, Fukui I, Ohmori H (2005) Tonotopic specialization of auditory coincidence detection in nucleus laminaris of the chick. J Neurosci 25:1924-1934.

Kuwabara N, DiCaprio RA, Zook JM (1991) Afferents to the medial nucleus of the trapezoid body and their collateral projections. J Comp Neurol 314:684-706.

Leão RM, Kushmerick C, Pinaud R, Renden R, Li GL, Taschenberger H, Spirou G, Levinson SR, von Gersdorff (2005) Presynaptic $\mathrm{Na}^{+}$channels: locus, development and recovery from inactivation at a highfidelity synapse. J Neurosci 25:3724-3738.

Leão RN, Leão RM, da Costa LF, Rock Levinson S, Walmsley B (2008) A novel role for MNTB neuron dendrites in regulating action potential amplitude and cell excitability during repetitive firing. Eur $\mathbf{J}$ Neurosci 27:3095-3108.

Leão KE, Leão RN, Deardorff AS, Garrett A, Fyffe R, Walmsley B (2010) Sound stimulation modulates high-threshold $\mathrm{K}^{+}$currents in mouse auditory brainstem neurons. Eur J Neurosci. 32:1658-1667.

Lenn NJ, Reese TS (1966) The fine structure of nerve endings in the nucleus of the trapezoid body and the ventral cochlear nucleus. Am J Anat 118:375-389.

Liberman LD, Liberman MC (2016) Postnatal maturation of auditory-nerve heterogeneity as seen in spatial gradients of synapse morphology in the inner hair cell area. Hear Res. 339:12-22.

Libersat F, Duch C (2004) Mechanisms of dendritic maturation. Mol Neurobiol 29:303-320.

Lorteije JA, Rusu SI, Kushmerick C, Borst JGG (2009) Reliability and precision of the mouse calyx of Held synapse. J Neurosci 29:13770-13784.

MacLeod KM, Carr CE (2012) Synaptic mechanisms of coincident detection. Springer Handbook of Auditory Research. Vol. 41, pg. 135-164Editors: Trussell, L.O., Popper, A.N., and Fay, R.R.

Madeja M (2000) Do neurons have a reserve of sodium channels for the generation of action potentials? A study on acutely isolated CA1 neurons from the guinea-pig hippocampus. Eur J Neurosci 12:1-7.

Major G, Evans JD, Jack JJB (1993) Solutions for transients in arbitrary branching cables: I. Voltage recording with a somatic shunt. Biophysical J 65:423-449.

Manis PB, Marx SO (1991) Outward currents in isolated ventral cochlea nucleus neurons. J Neurosci 11:2865-2880.

Martina M, Yao GL, Bean BP (2003) Properties and functional role of voltage-dependent potassium channels in dendrites of rat cerebellar Purkinje neurons. J Neurosci 23:5698-5707.

Mejia-Gervacio S, Collin T, Pouzat C, Tan YP, Llano I, Marty A (2007) Axonal speeding: shaping synaptic potentials in small neurons by the axonal membrane compartment. Neuron. 53:843-855. 
Morest DK (1973). Auditory neurons of the brain stem. Adv Otorhinolaryngol 20:337-356.

Nadeau H, Lester HA (2000) Two-compartment model for whole-cell data analysis and transient compensation. J Neurosci Methods 99:25-35.

Nadeau H, Lester HA (2002) NRSF causes cAMP-sensitive suppression of sodium current in cultured hippocampal neurons. J Neurophysiol 88:409-421.

Nicoll A, Larkman A, Blakemore C (1993) Modulation of EPSP shape and efficacy by intrinsic membrane conductances in rat neocortical pyramidal neurons in vitro. J Physiol 468:693-710.

Perney TM, Kaczmarek LK (1997) Localization of a high threshold potassium channel in the rat cochlear nucleus. J Comp Neurol 386:178-202.

Rall W (1969) Time constants and electrotonic length of membrane cylinders and neurons. Biophysical J 9:1483-1508.

Renden R, Taschenberger H, Puente N, Rusakov DA, Duvoisin R, Wang L-Y, Lehre KP, von Gersdorff H (2005) Glutamate transporter studies reveal the pruning of metabotropic glutamate receptors and the absence of AMPA receptor desensitization at mature calyx of Held synapse. J Neurosci 25:8482-8497.

Reyes A (2001) Influence of dendritic conductances on the input-output properties of neurons. Annu Rev Neurosci 24:653-675.

Rowland KC, Irby NK, Spirou GA (2000) Specialized synapse-associated structures within the calyx of Held. J Neurosci 20:9135-9144.

Sätzler K, Söhl LF, Bollmann JH, Borst JG, Frotscher M, Sakmann B, Lübke JH (2002) Three-dimensional reconstruction of a calyx of Held and its postsynaptic principal neuron in the medial nucleus of the trapezoid body. J Neurosci 22:10567-10579.

Schneggenburger R, Meyer AC, Neher E (1999) Released fraction and total size of a pool of immediately available transmitter quanta at a calyx synapse. Neuron 23:399-409.

Scott LL, Mathews PJ, Golding NL (2005) Posthearing development refinement of temporal processing in principal neurons of the medial superior olive. J Neurosci 25:7887-7895.

Smith PH, Joris PX, Yin TC (1998) Anatomy and physiology of principal cells of the medial nucleus of the trapezoid body (MNTB) of the cat. J Neurophysiol 79:3127-3142.

Spirou GA, Brownell WE, Zidanic M (1990) Recordings from cat trapezoid body and HRP labeling of globular bushy cell axons. J Neurophysiol 63:1169-1190.

Spirou GA, Chirila FV, von Gersdorff H, Manis PB (2008) Heterogeneous $\mathrm{Ca}^{2+}$ influx along the adult calyx of Held: a structural and computational study. Neuroscience 154:171-185.

Taschenberger H, von Gersdorff H (2000) Fine-tuning an auditory synapse for speed and fidelity: developmental changes in presynaptic waveform, EPSC kinetics, and synaptic plasticity. J Neurosci 20:9162-9173.

Taschenberger H, Leão RM, Rowland KC, Spirou GA, von Gersdorff H (2002) Optimizing synaptic architecture and efficiency for high-frequency transmission. Neuron 36:1127-1143.

Tollin DJ (2003) The lateral superior olive: A functional role in sound source localization. The Neuroscientist 9:127-143. 
von Gersdorff H, Borst JG (2002) Short-term plasticity at the calyx of Held. Nat Rev Neurosci 3:53-64.

Wang LY, Gan L, Forsythe ID, Kaczmarek LK (1998) Contribution of the Kv3.1 potassium channel to high-frequency firing in mouse auditory neurones. J Physiol 509:183-194.

Wu SH and Kelly JB (1993) Response of neurons in the lateral superior olive and medial nucleus of the trapezoid body to repetitive stimulation: Intracellular and extracellular recordings from mouse brain slice. Hear Res 68:189-201.

Yang B, Desai R, Kaczmarek LK (2007) Slack and Slick K(Na) channels regulate the accuracy of timing of auditory neurons. J Neurosci 27:2617-27.

Yang Y, Ramamurthy B, Neef A, Xu-Friedman MA (2016) Low somatic sodium conductance enhances action potential precision in time-coding auditory neurons. J Neurosci 36:11999-12009.

\section{Figure legends}

Figure 1. 3D reconstruction of mouse MNTB principal cells. (A) Eight MNTB cells from postnatal day P30 reconstructed from a serial block-face scanning electron microscopy image volume, including cell bodies (tan), dendrites (multiple colors), and axons (rose). The dendrites (1-3 per cell) tend to be long and straight, with relatively few branches and a fairly constant diameter (A, inset graph). Dendrites proximal to one another exhibit similar orientations, as do the MTNB cell axons. The axon from the left-most cell takes a tortuous path (white arrowheads) before it aligns with the axon of a neighboring cell and is clipped at the edge of the image volume. A third axon (black arrowhead) appears to take a similar trajectory to the first two axons, but is also quickly clipped at the edge of the image volume as well. The remaining five axons align with one another and take a similar path exiting the image volume to the right, forming an axon bundle. (B, C) Two cells (white arrows) isolated in the lower panels highlight the sparsity of dendrites and lack of dendritic branches or spines. Additionally, myelin (purple) can be seen ensheathing the axons of each of the cells, revealing that the axon initial segment is bare of myelin. Scale bars $=20 \mu \mathrm{m}$.

Figure 2: Dendritic inputs are dense proximal to the MNTB soma and become sparse at more distal locations. (A) MNTB principal cell at P30 with soma (tan), axon with myelin (maroon and purple, respectively), and 3 thin dendrites (brown), with only one showing a bifurcation and no distinct dendritic spines. Inputs (green spheres) are found clustered either at dendritic swellings (lower left inset) or at the initial emergence of the dendrite from the soma (upper inset). Inputs along the thin main dendritic body are sparse (lower right inset). Panels $\mathrm{C}$ and $\mathrm{D}$ represent electron microscopy images taken from the locations in the lower right panel denoted by the white filled arrowhead and open arrowhead, respectively. (B) The number of unique dendritic inputs falls off quickly as a function of distance from the soma along the dendrite ( $\mathrm{n}=16$ dendrites from 8 unique MNTB cells). (C) EM of location along dendrite in (A) denoted in lower right panel by filled white arrowhead. The dendrite (d, brown) is innervated by two distinct boutons (b1 and b2, green) filled with round vesicles. The dendritic membrane not innervated is covered by thin glial processes extending from a glial projection (g, yellow). (D) EM of location along dendrite in (A) denoted in lower right panel by open white arrowhead. The dendrite (d) in this location is completely ensheathed by glial processes (g, yellow), preventing two potential boutons (blue) from making contact. Scale bars: A, $20 \mu \mathrm{m}$; A (insets), $5 \mu \mathrm{m}$. C-D, $0.5 \mu \mathrm{m}$.

Figure 3. Current clamp responses of MNTB principal cells. (A,B) The voltage responses (black) recorded from a P20 neuron after step current injections (red; $50 \mathrm{pA}$ steps) at $24^{\circ} \mathrm{C}$. At the threshold a single action potential spike is triggered by a step depolarization. The vertical dotted line marks the membrane potential values at the onset of the $\mathrm{I}_{\mathrm{h}}$ current plotted as closed circles in panel B and the dotted rectangle shows the time period over which the steady-state membrane potential was measured (open triangles in panel B; values plotted as mean $\pm \mathrm{SEM}, \mathrm{n}=6$ ). The slope of the dashed line in panel B (the I-V curve) is a measure of the average input resistance of the cell $\left(R_{m}=201 M \Omega\right)$. The deviation from a straight 
line at depolarized potentials is due to the activation of a low threshold potassium current $\left(\mathrm{I}_{\mathrm{KLT}}\right)$ and at hyperpolarized potentials is due to the activation of $\mathrm{I}_{\mathrm{h}}$.

(C) A 2 ms current injection ( +50 and $+150 \mathrm{pA}$ in red, bottom) generates rapid EPSP-like voltage

responses (black). The decay of the transient voltage response is well fit by a double exponential function (superimposed red trace). The respective fast and slow time constants, and the percent contribution of the fast component, are shown. The same data can also be well fit by a Rall function (dashed green curve). (D) The voltage responses from a P28 neuron after step current injections (red; $100 \mathrm{pA}$ steps) at $35^{\circ} \mathrm{C}$. At the threshold a single action potential spike is triggered by a step depolarization.

(E) Same as in panel B but for P28 neurons at $35^{\circ} \mathrm{C}$. The slope of the dashed line $\left(\mathrm{R}_{\mathrm{m}}=132 \mathrm{M} \Omega\right)$ is lower than for panel B. This decrease of input resistance is also evident in panel D.

(F) The effect of temperature on membrane passive properties. Current clamp recordings from the same cell in response to a step current injection $\left(-50 \mathrm{pA}\right.$; black trace, $\left.24^{\circ} \mathrm{C} ; \mathrm{red}, 35^{\circ} \mathrm{C}\right)$. The dashed superimposed lines are best fits to a double exponential function with the respective fast $\left(\tau_{\mathrm{f}}\right)$ and slow $\left(\tau_{\mathrm{s}}\right)$ time constants shown on the right. The percent contribution of the fast component is also shown. The mean membrane time constant is faster at $35^{\circ} \mathrm{C}$. Arrows indicate spontaneous postsynaptic currents (PSC) in both traces.

Figure 4. Voltage clamp responses of MNTB principal cells. Whole-cell recordings showing the passive properties of the MNTB neurons in response to $10 \mathrm{mV}$ hyperpolarizing voltage step. $\left(\mathbf{A}_{\mathbf{i}}\right)$ Postnatal day 10 (P10) neuron showing a bi-exponential capacitive current decay (fit = blue curve) and a relatively small steady-state current during the voltage step. The membrane capacitances of the fast and medium components were $13 \mathrm{pF}$ and $18 \mathrm{pF}$, respectively. $\left(\mathbf{B}_{\mathbf{i}}\right)$ Recording from a P23 neuron showing tri-exponential capacitive current decay (fit $=$ green curve) and a relatively large steady-state current during the voltage step. The membrane capacitances of the fast, medium, and slow components were $9 \mathrm{pF}, 12 \mathrm{pF}$, and $21 \mathrm{pF}$, respectively. ( $\mathbf{A}_{\mathbf{i i}}$ and $\mathbf{B}_{\mathrm{ii}}$ ) Capacitive currents from the same P10 and P23 neurons along with single exponential (red curve), bi-exponential (blue curve), and tri-exponential (green curve) fits. Inset shows the enlarged traces for clarity. $\left(\mathbf{A}_{\mathrm{iii}}\right.$ and $\left.\mathbf{B}_{\mathrm{iii}}\right)$ Difference between the measured capacitive currents and the fit with single, bi, and tri- exponential functions for the same P10 and P23 neurons. For the P10 neuron, a biexponential fit was sufficient to minimize residual current (blue trace), whereas for the P23 neuron a triexponential fit (green trace) was required. (C) Graph summarizing the mean decay time constants of the fast and medium components with their associated amplitudes and capacitance values (P9-11; $\mathrm{n}=26$ ). (D) Graph summarizing the mean decay time constants of the fast, medium, and slow components with their associated amplitudes, and capacitance values (P21-24; $n=16)$. Values are expressed as mean \pm SEM.

Figure 5. Confocal fluorescence images of MNTB neurons filled with Alexa fluor 555. ( $\left.\mathbf{A}_{\mathbf{i} \text {-ii }}\right)$ Fluorescence images showing the morphology of a P10 MNTB neuron (2 different frames). ( $\left.\mathbf{B}_{\mathbf{i - i i}}\right)$ Fluorescence images showing the morphology of a P23 MNTB neuron (2 different frames). ( $\mathbf{A}_{\text {iii }}$ and $\mathbf{B}_{\text {iii }}$ ) Maximum intensity projection of 10 image planes showing the morphology of the same P10 and P23 MNTB neurons. The P23 neuron shows comparatively longer and bifurcated dendrites than P10. (C) Graph summarizing the mean dendritic length, diameter of the soma, and axonal length (traced in the field of view) of P9-11 ( $\mathrm{n}=11)$ and P21-24 ( $\mathrm{n}=7)$ MNTB neurons. Asterisk indicate a significant difference in length ( $\mathrm{p}=0.03)$.

Figure 6. The passive properties of MNTB neurons which lack axon and dendrite. $\left(\mathbf{A}_{\mathbf{i}}\right) \mathrm{P} 10$ neuron displaying capacitive current with mono-exponential decay and a small steady-state current upon $-10 \mathrm{mV}$ voltage step. $\left(\mathbf{A}_{\mathbf{i i}}\right)$ Fluorescence image of the representative neuron whose recording is shown above. The arrow head points to very small neurite process (either a cut axon or a small dendrite stub). (B) Bar graph summarizing the mean decay time constants of the capacitive current from neurons lacking any process. Both values (fitted and calculated using the membrane time constant formula) are similar ( $\mathrm{p}=0.23$ ). (C) Graph summarizing the mean amplitude and capacitance $(\mathrm{P} 9-17 ; \mathrm{n}=4)$. (D) Summary graph of all recorded cells showing the correlation of capacitive current decay with input resistance $\left(\mathrm{R}_{\mathrm{I}}\right)$.

Figure 7. Decay kinetics of synaptic currents and synaptic potentials at younger and older ages during afferent fiber stimulation $(0.1 \mathrm{~Hz}) .\left(\mathbf{A}_{\mathbf{i}}\right.$ and $\left.\mathbf{B}_{\mathbf{i}}\right)$ Evoked excitatory postsynaptic currents (EPSCs) of a P11 and a P23 MNTB neuron (grey trace) with their fitted decay shown in black. Inset shows enlarged trace for 
clarity. (C) Summary graph showing mean decay time constants of EPSCs at P9-11 ( $\mathrm{n}=14)$ and at P21-24 $(\mathrm{n}=8)$. $\left(\mathbf{A}_{\mathrm{ii}}\right.$ and $\left.\mathbf{B}_{\mathrm{ii}}\right)$ Evoked excitatory postsynaptic potentials (EPSPs) of the same P11 and P23 MNTB neuron (grey trace) with their fitted decay kinetics (black). Inset shows enlarged trace for clarity.

(D) Summary graph showing the mean decay time constants of EPSPs at P9-11 $(n=8)$ and at P21-24 (n=6).

Figure 8. Decay kinetics of synaptic currents and synaptic potentials in MNTB neurons during $100 \mathrm{~Hz}$ train stimulation (50 stimuli). ( $\mathbf{A}_{\mathbf{i}}$ and $\mathbf{B}_{\mathbf{i}}$ ) Evoked EPSCs (grey traces) of P11 and P23 MNTB neurons with their fitted decay kinetics (black). ( $\mathbf{A}_{\mathrm{ii}}$ and $\mathbf{B}_{\mathrm{ii}}$ ) Evoked EPSPs of the same P11 and P23 MNTB neuron (grey trace) shown above and their fitted decay kinetics (black). P23 neuron showing faster bi-exponential decay than P11 neuron.

Figure 9. Graph summarizing the relationship of decay kinetics of synaptic currents and synaptic potentials with respect to $\mathrm{R}_{\mathrm{I}}$. (A) Summary graph showing lack of correlation of weighted decay time constants of EPSCs and $\mathrm{R}_{\mathrm{I}}$ of P9-11 (blue; $\mathrm{n=12}$ ) and P21-24 (red; $\mathrm{n=9}$ ) MNTB neurons. (B) Summary graph showing the correlation of weighted decay time constants of EPSPs and $\mathrm{R}_{\mathrm{I}}$ of P9-11 (black; $\mathrm{n}=15$ ) and P21-24 (red; $\mathrm{n}=9$ ) MNTB neurons.

Figure 10. Passive properties of older MNTB neurons with axons and with or without long dendrites. $\left(\mathbf{A}_{\mathbf{i}}\right)$ P24 neuron gives a bi-exponential capacitive current decay (fit in green) and a relatively small steadystate current during the voltage step, indicating a high input resistance. ( $\mathbf{A}_{\mathrm{ii}}$ and $\mathbf{A}_{\mathrm{iii}}$ ) Evoked EPSCs and EPSPs of the same neuron with its associated decay kinetics. $\left(\mathbf{A}_{\mathbf{i v}}\right)$ Fluorescence image showing the morphology of a typical neuron which possesses an axon but lacks dendrites. The arrow points to the axon and the arrowhead to a putative dendrite stub. (B) Summary graph showing the relationship of triexponential and bi-exponential capacitive current decay with respect to EPSCs and EPSPs (P21-24; n=5 cells in each case). EPSPs significantly decay faster with tri-exponential capacitive current $(\mathrm{p}=0.0005)$. $\left(\mathbf{C}_{\mathbf{i}}\right.$ and $\left.\mathbf{C}_{\mathbf{i i}}\right)$ Averaged evoked EPSP from older neurons with dendrite (black; $\mathrm{n}=5$ ) and without dendrite (red; $\mathrm{n}=5$ ). Note that the neurons with dendrite EPSP decays $\sim 5$ times faster than neurons lacking dendrites.

Figure 11. Model neuron response to simulated single calyceal EPSPs. (A) Simulated EPSPs response of a modeled MNTB neuron with different dendrite lengths ( $\left.\mathbf{A}_{\text {i-ii-iii-iv }}: 10,20,40,80 \mu \mathrm{m}\right)$ and with different leak conductance on the dendrite (black: $62.5 \mu \mathrm{S} / \mathrm{cm}^{2}$, red: $125 \mu \mathrm{S} / \mathrm{cm}^{2}$, blue: $250 \mu \mathrm{S} / \mathrm{cm}^{2}$, green: $500 \mu \mathrm{S} / \mathrm{cm}^{2}$ ). (B) Simulated EPSPs with different leak conductance, but without dendrite (black: $62.5 \mu \mathrm{S} / \mathrm{cm}^{2}$, red: 125 $\mu \mathrm{S} / \mathrm{cm}^{2}$, blue: $250 \mu \mathrm{S} / \mathrm{cm}^{2}$, green: $500 \mu \mathrm{S} / \mathrm{cm}^{2}$ ). (C) Simulated EPSPs with different dendrite lengths and with constant leak conductance $\left(250 \mu \mathrm{S} / \mathrm{cm}^{2}\right)$. Note that the simulated EPSPs decay faster with larger leak and longer dendrites, which simulates the behavior of the experimental results. 


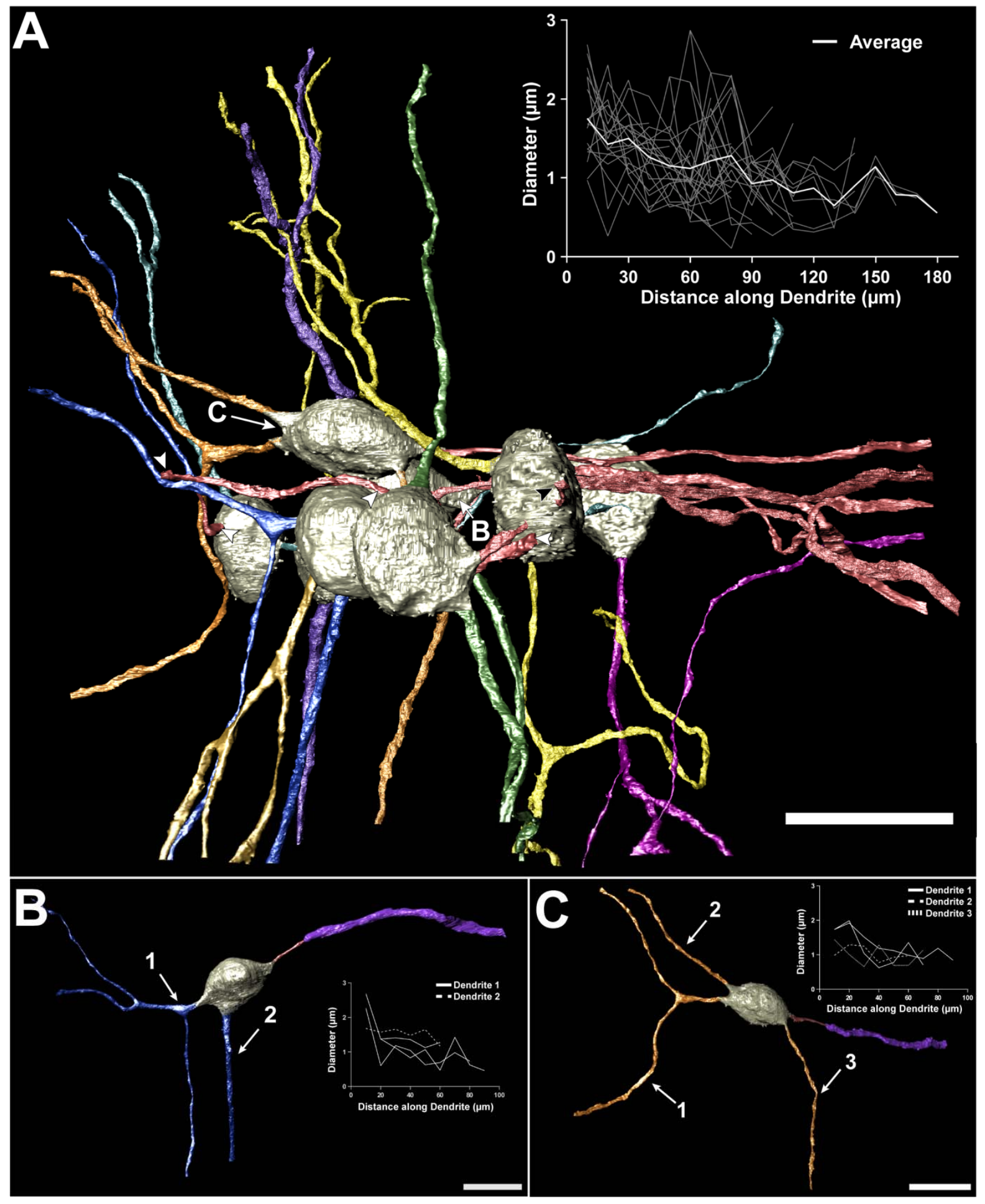

Figure 1 

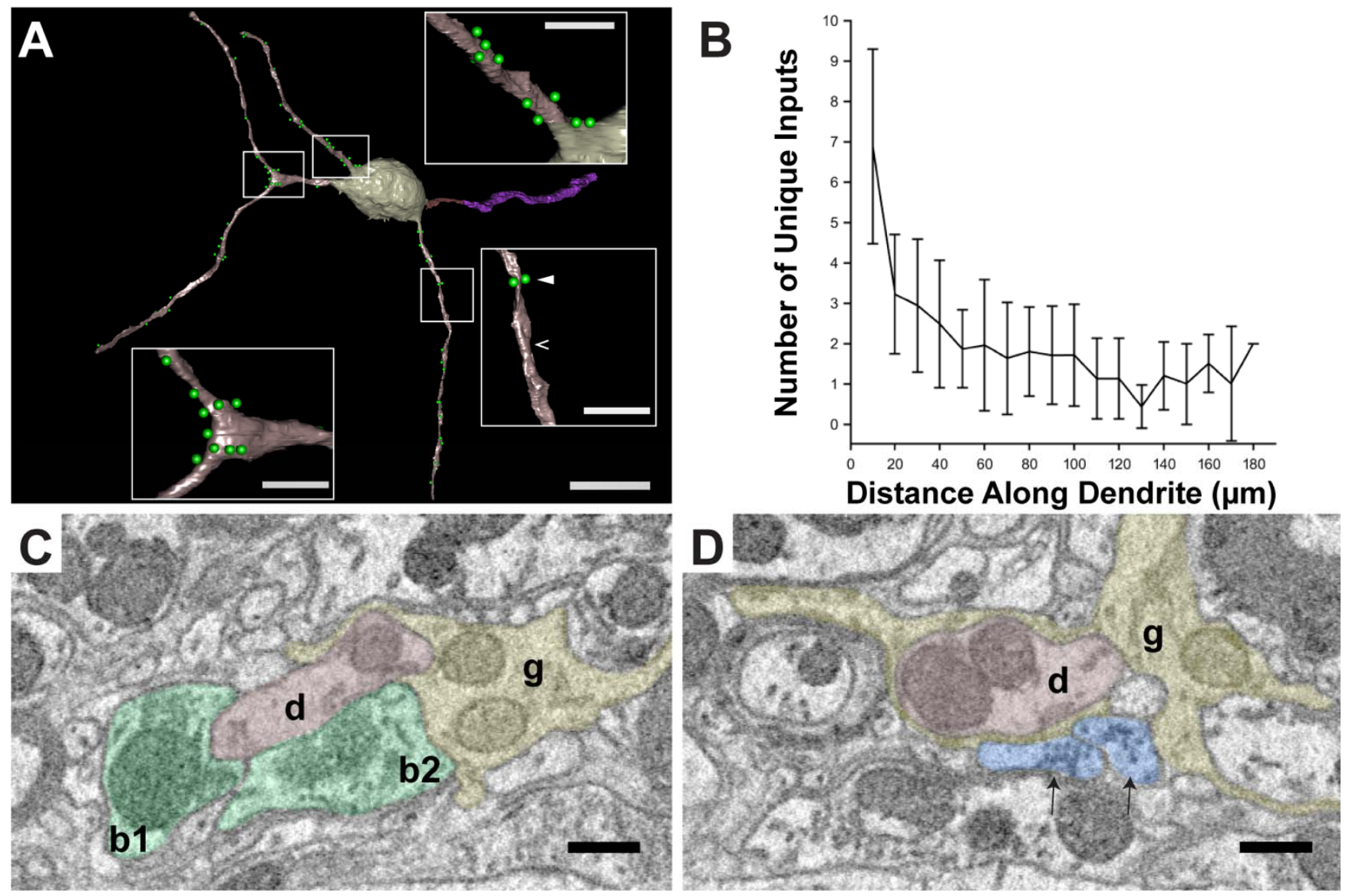

\section{Figure 2}



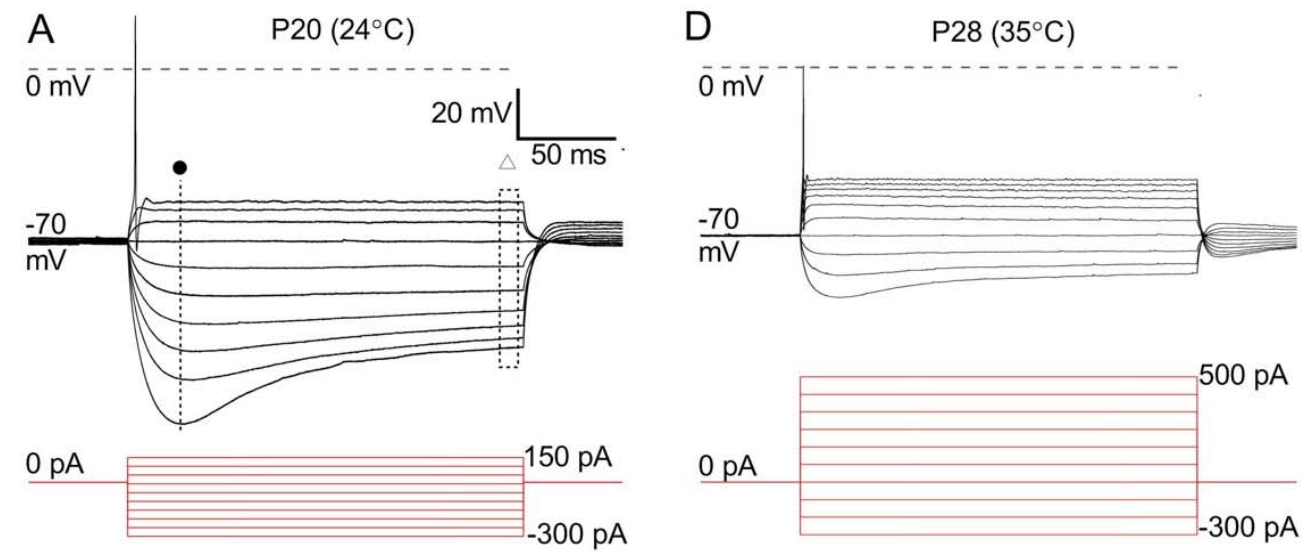

B

P20-28 $\left(24^{\circ} \mathrm{C}\right)$
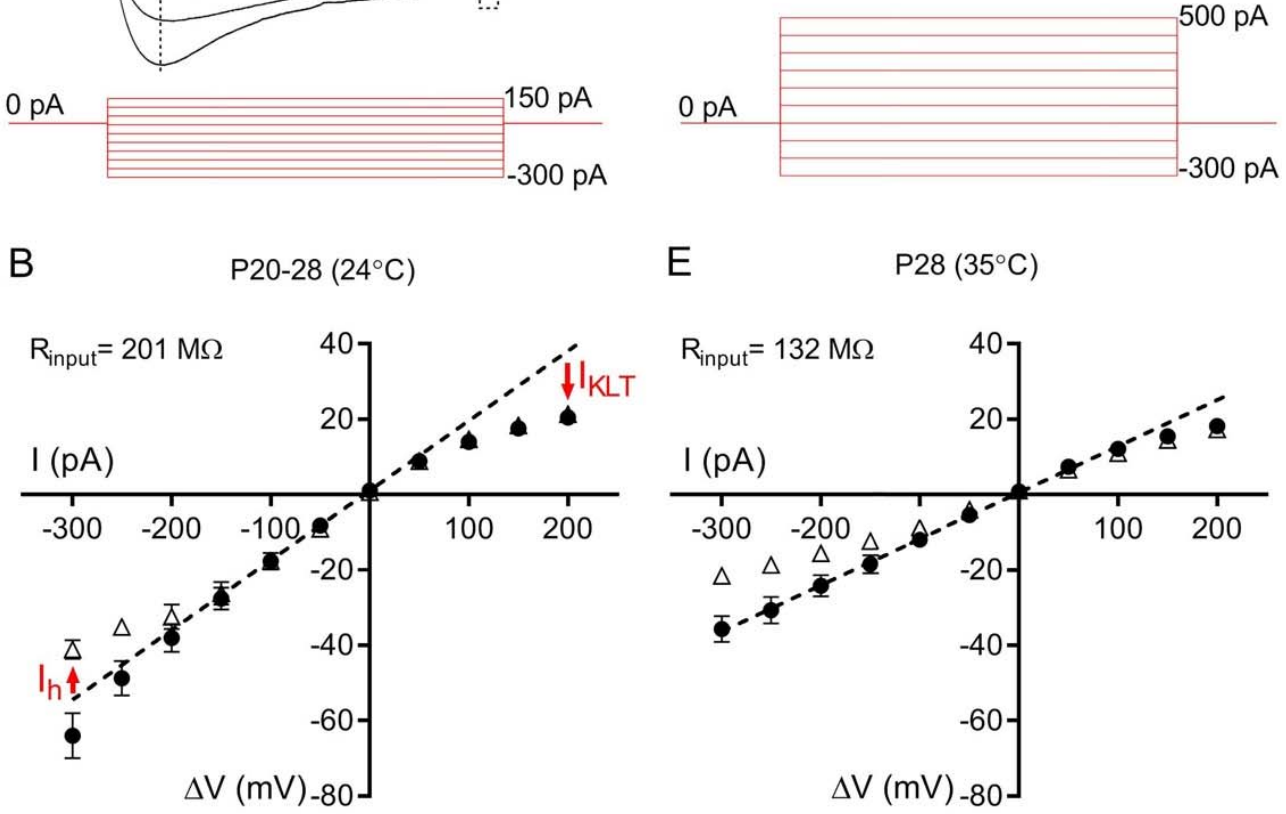

$E$

$\mathrm{P} 28\left(35^{\circ} \mathrm{C}\right)$

C $\mathrm{P} 20\left(24^{\circ} \mathrm{C}\right)$
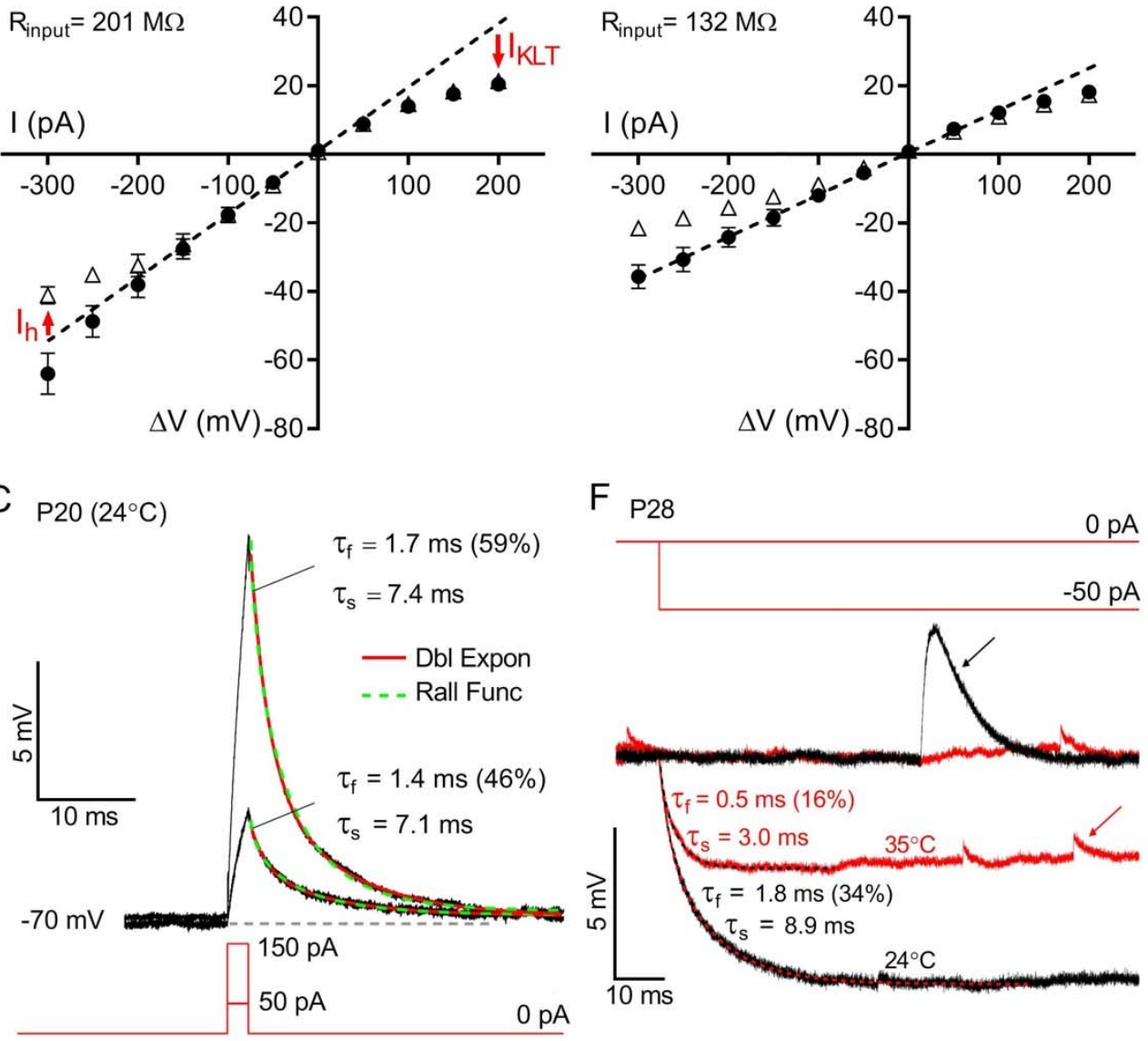

$\mathrm{F}$
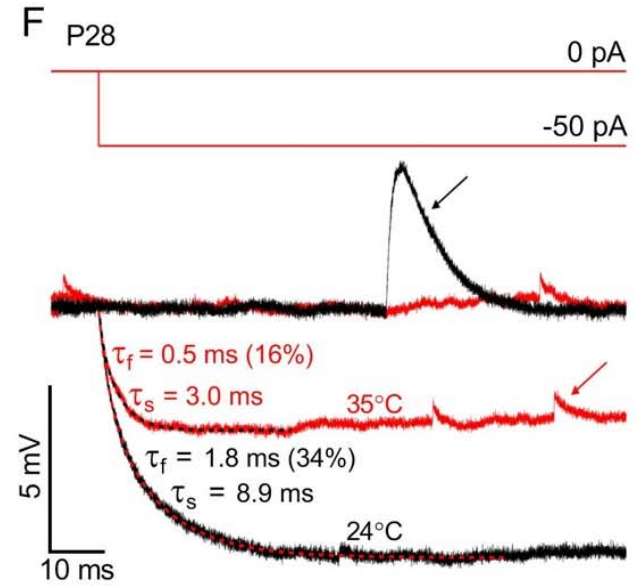

Figure 3 


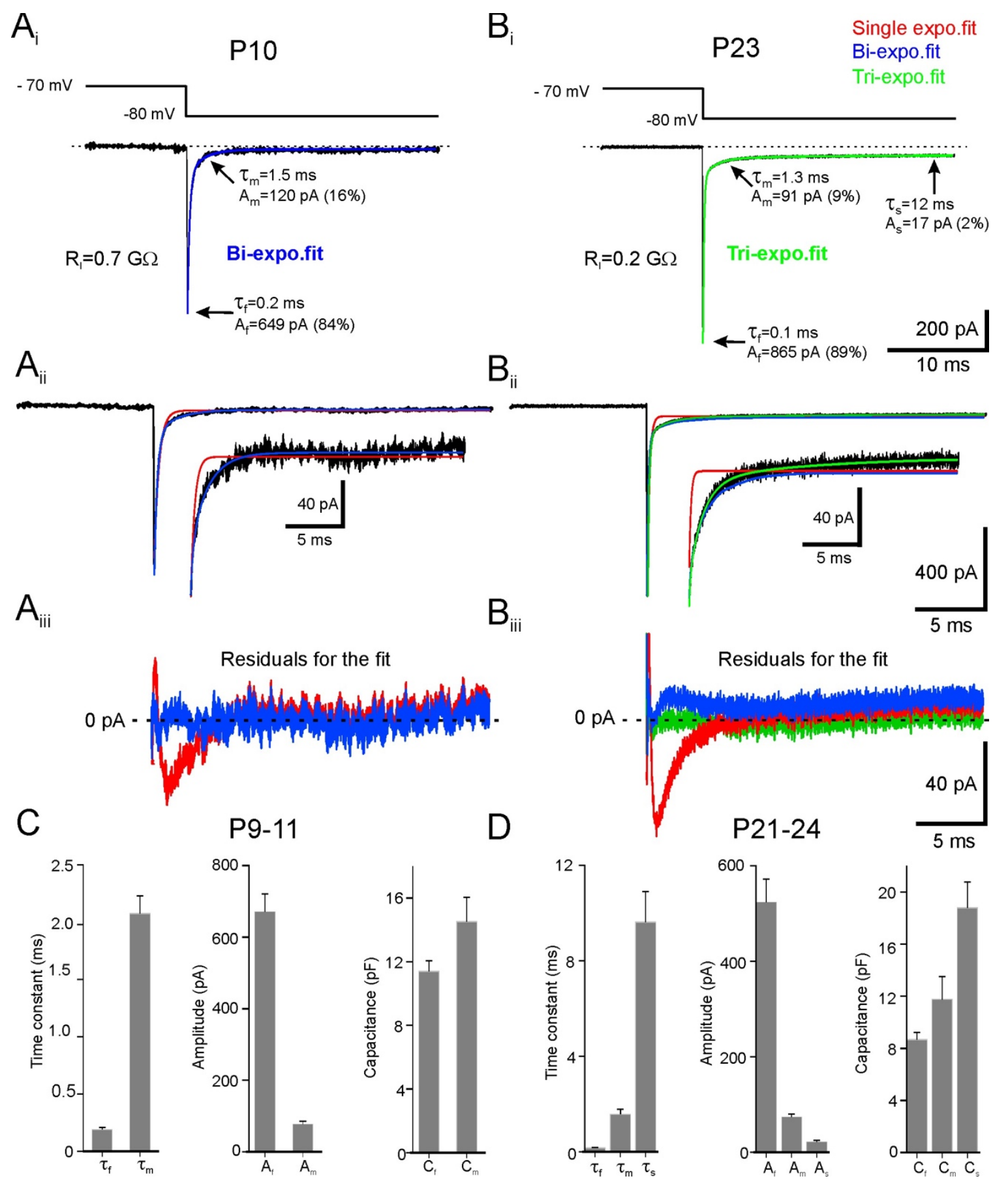

\section{Figure 4}




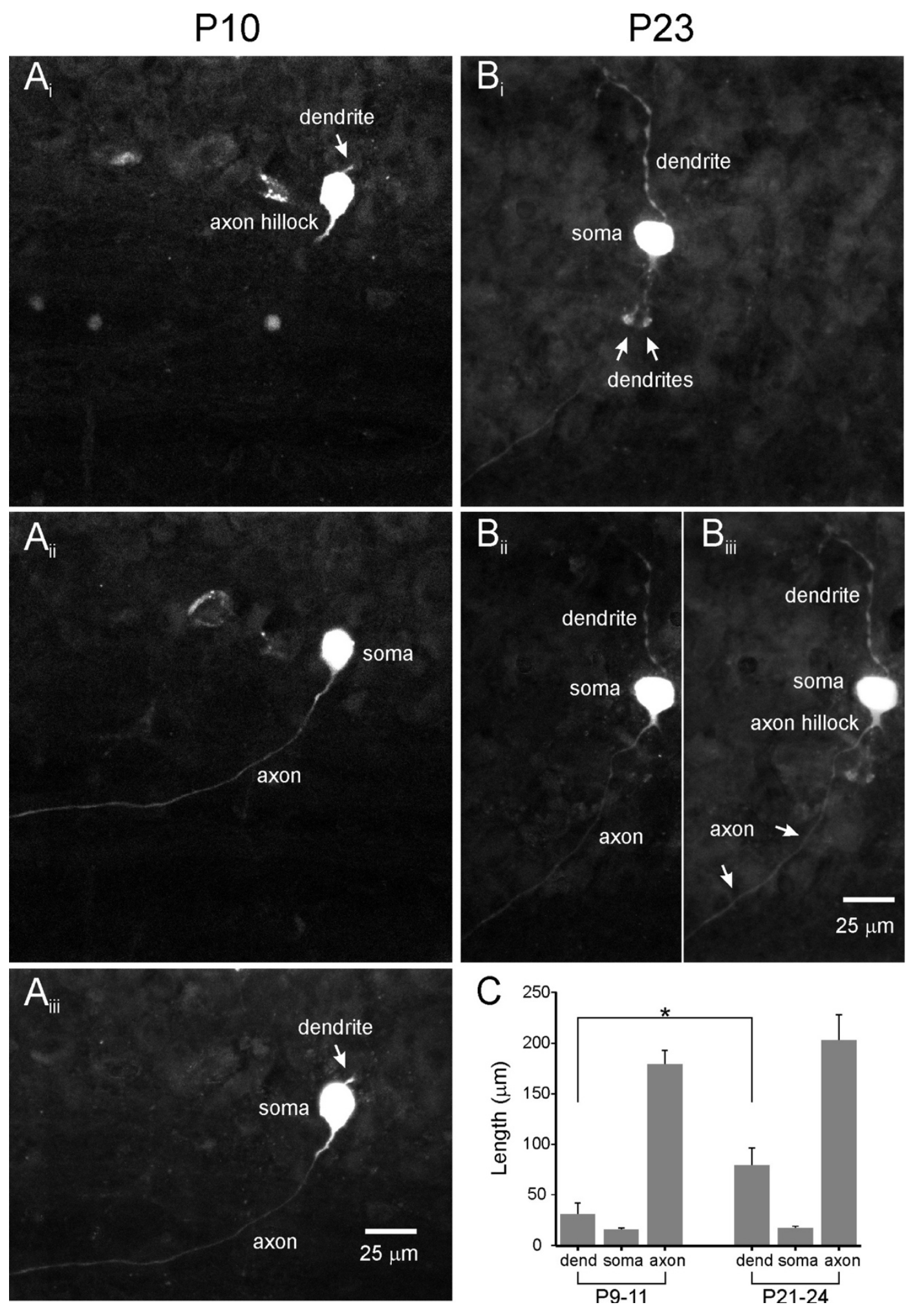

\section{Figure 5}




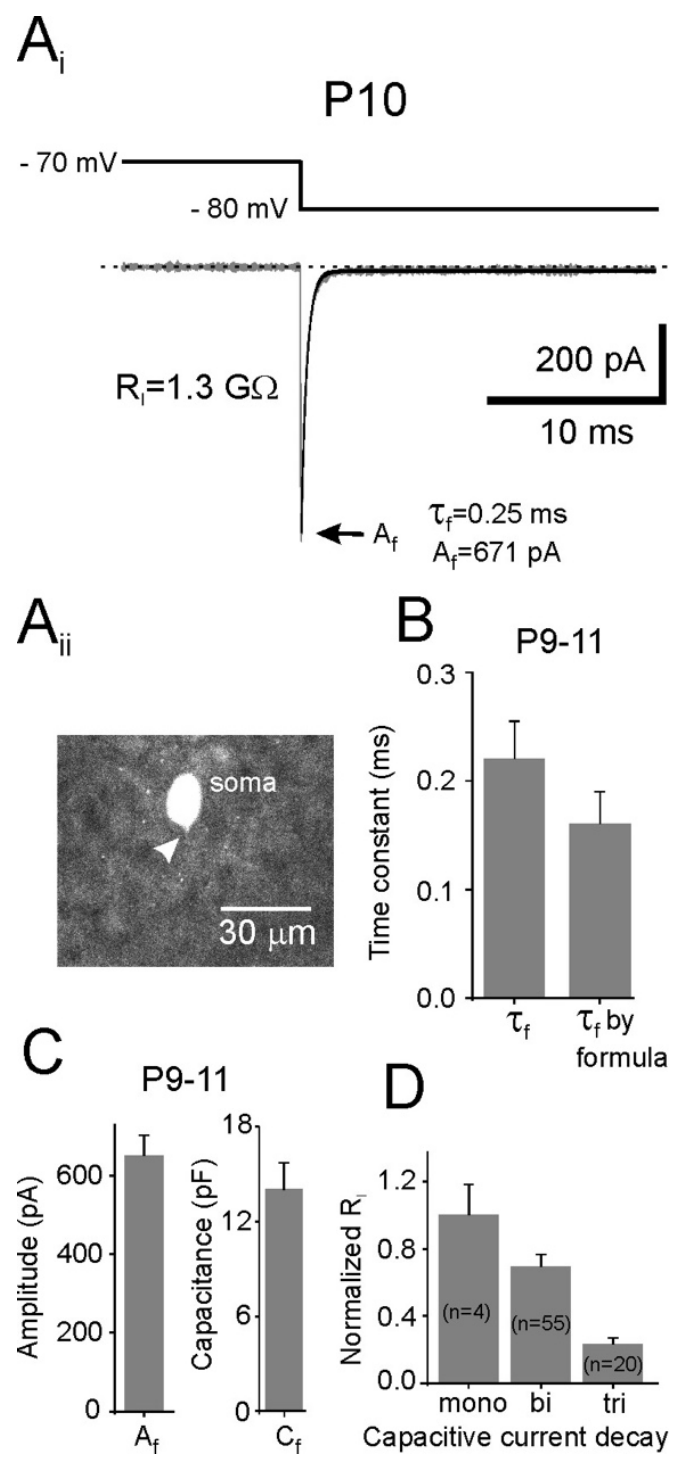

Figure 6 


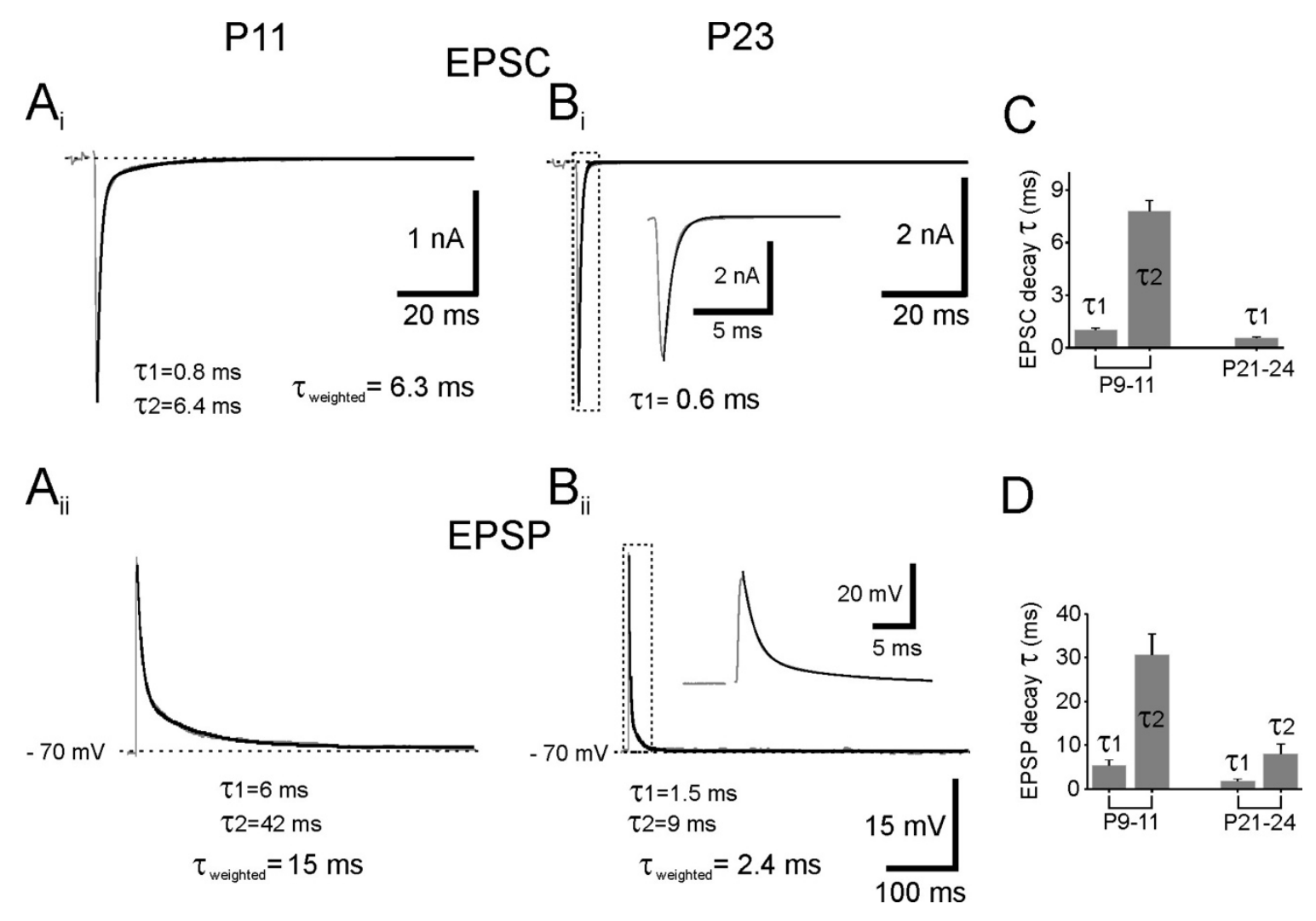

Figure 7 


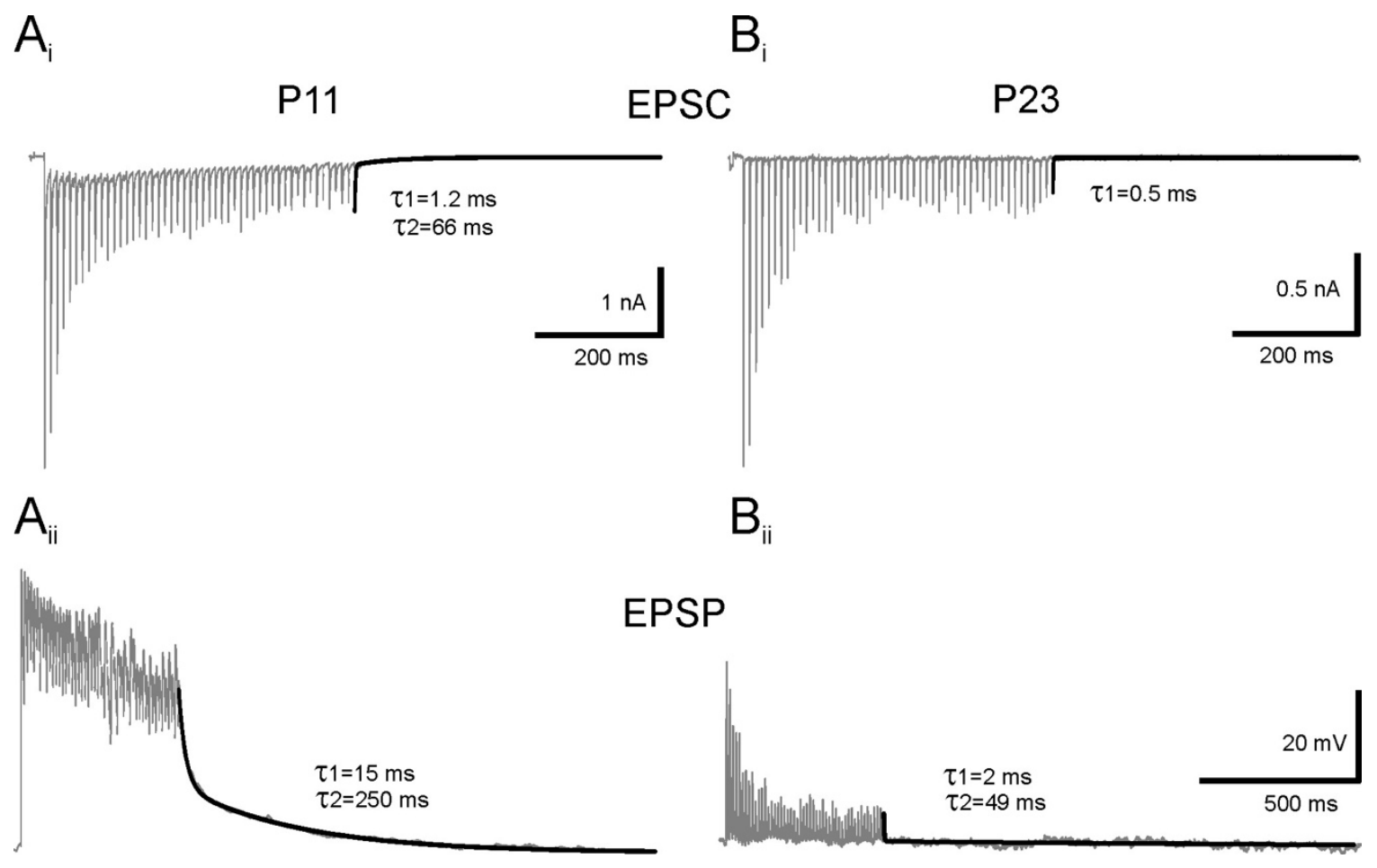

Figure 8 


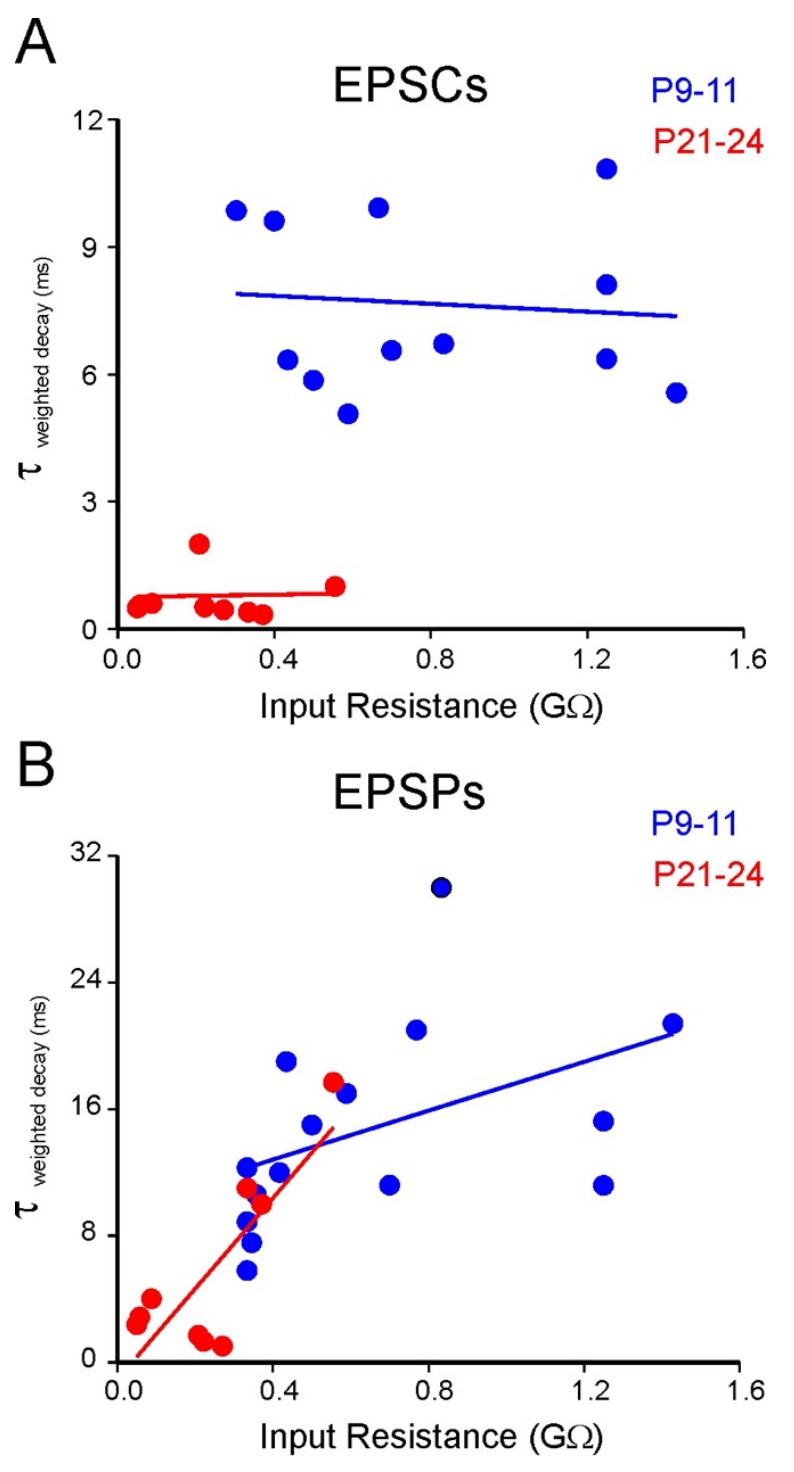

Figure 9 

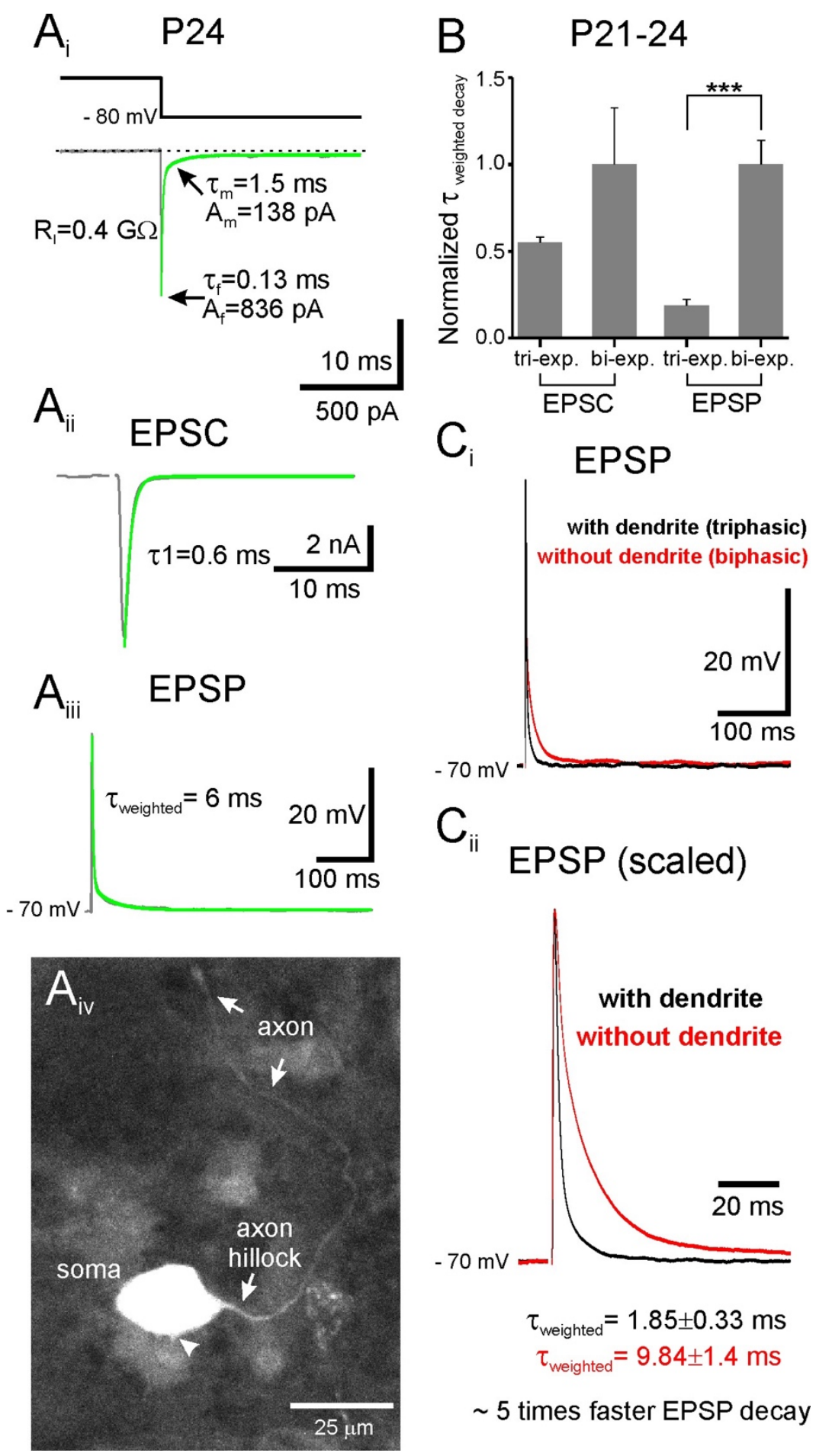

$\sim 5$ times faster EPSP decay

Figure 10 


\section{Modeled EPSP}

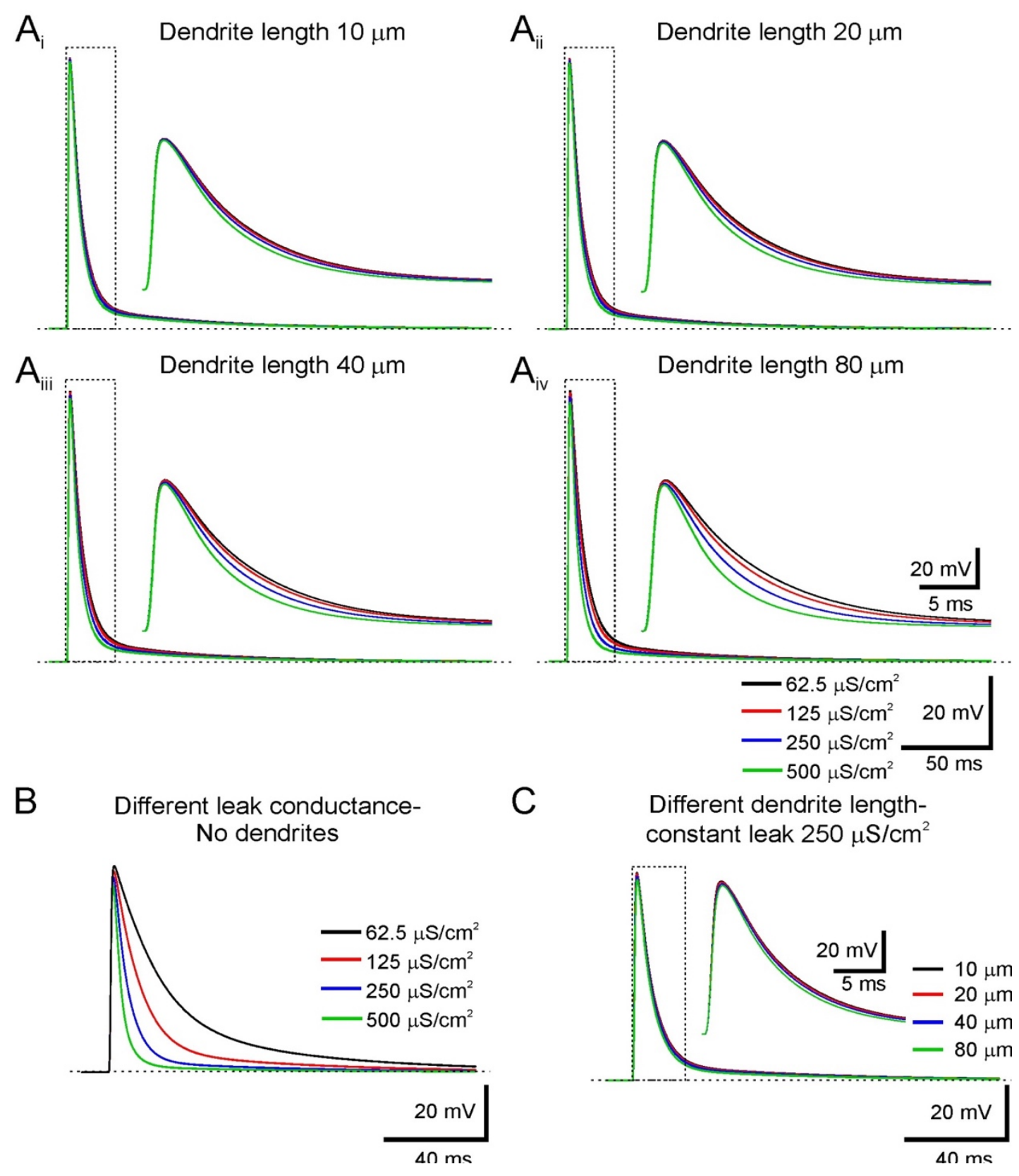

Figure 11 


\begin{tabular}{|c|c|c|c|c|c|}
\hline & \multicolumn{5}{|c|}{ Surface area $\left(\mu \mathrm{m}^{2}\right)$ of MNTB Principal Cells (P30; $\left.n=8\right)$} \\
\hline & Total & Soma & Dendrites & Axon & Axon Initial Segment \\
\hline \multirow{8}{*}{ 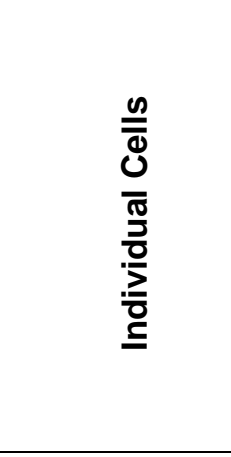 } & 2858 & 1400 & 1341 & 117 & 117 \\
\hline & 2480 & 1502 & 847 & 130 & 130 \\
\hline & 4667 & 2226 & 2397 & 43 & 43 \\
\hline & 4066 & 1456 & 1716 & 895 & 145 \\
\hline & 3706 & 1514 & 1114 & 1078 & 119 \\
\hline & 3614 & 1467 & 1282 & 865 & 51 \\
\hline & 3419 & 1287 & 1464 & 668 & 85 \\
\hline & 3048 & 1446 & 1016 & 587 & 183 \\
\hline AVG \pm SEM & $3482 \pm 230$ & $1537 \pm 95$ & $1397 \pm 161$ & $548 \pm 133$ & $109 \pm 16$ \\
\hline$C_{m}(p F) \pm S E M$ & $34.8 \pm 2.3$ & $15.4 \pm 0.9$ & $14.0 \pm 1.6$ & $5.5 \pm 1.3$ & $1.1 \pm 0.2$ \\
\hline
\end{tabular}

Table 1. MNTB principal cell surface area and membrane capacitance at postnatal day 30 (P30). Data from 8 different cells is shown for the total surface area and for the separate surface areas of soma, dendrites and axon, as well as the axon initial segment.

\begin{tabular}{|c|c|c|c|c|c|c|c|c|c|c|c|}
\hline Postnatal age & $\tau_{f}(\mathrm{~ms})$ & $\tau_{\mathrm{m}}(\mathrm{ms})$ & $\tau_{\mathrm{s}}(\mathrm{ms})$ & $C_{f}(p F)$ & $\mathrm{C}_{\mathrm{m}}(\mathrm{pF})$ & $\mathrm{C}_{\mathrm{s}}(\mathrm{pF})$ & $A_{f}(p A)$ & $A_{m}(p A)$ & $A_{s}(p A)$ & $\%$ of cells ${ }^{a}$ & $\mathrm{R}_{\mathrm{l}}(\mathrm{G} \Omega)$ \\
\hline$P 6-6(n=5)$ & $0.15 \pm 0.04$ & $2.0 \pm 0.30$ & & $10 \pm 1.4$ & $14 \pm 1.5$ & & $800 \pm 120$ & $63 \pm 11$ & & $100 \%$ & $0.8 \pm 0.1$ \\
\hline P9-11 $(n=26)$ & $0.2 \pm 0.01$ & $2.0 \pm 0.15$ & & $11 \pm 0.7$ & $14 \pm 1.5$ & & $671 \pm 49$ & $78 \pm 8$ & & $87 \%$ & $0.6 \pm 0.06$ \\
\hline P16-17 $(n=10)$ & $0.2 \pm 0.02$ & $2.1 \pm 0.4$ & & $9.64 \pm 1.0$ & $15 \pm 2.0$ & & $669 \pm 80$ & $78 \pm 15$ & & $71 \%$ & $0.6 \pm 0.1$ \\
\hline $\mathbf{P 2 1 - 2 4}(n=16)$ & $0.15 \pm 0.01$ & $1.6 \pm 0.2$ & $9.6 \pm 1.3$ & $9 \pm 0.6$ & $12+1.8$ & $18 \pm 2$ & $524 \pm 49$ & $74 \pm 6$ & $22 \pm 3$ & $46 \%$ & $0.2 \pm 0.03$ \\
\hline $\mathbf{P 2 1 - 2 4}(\mathrm{n}=19)$ & $0.2 \pm 0.01$ & $2.2 \pm 0.18$ & & $9.1 \pm 0.6$ & $16 \pm 1.5$ & & $593 \pm 58$ & $82 \pm 7$ & & $54 \%$ & $0.5 \pm 0.09$ \\
\hline $\begin{array}{l}\text { MNTB neuron } \\
\text { without axon } \\
\text { and dendrite } \\
\quad(n=4)\end{array}$ & $0.2+0.03$ & & & $14 \pm 1.7$ & & & $650 \pm 52$ & & & & $0.91 \pm 0.1$ \\
\hline $\begin{array}{c}\text { MNTB neuron } \\
\text { with axon and } \\
\text { without dendrite } \\
\quad(n=5)\end{array}$ & $0.15 \pm 0.02$ & $1.9 \pm 0.18$ & & $11.5 \pm 0.2$ & $18 \pm 0.04$ & & $767 \pm 122$ & $97 \pm 14$ & & & $0.55 \pm 0.12$ \\
\hline
\end{tabular}

Table 2. Capacitive current decay time constants and input resistance during postnatal development.

The $\%$ of cells ${ }^{\mathbf{a}}$ at different postnatal ages:

At P5-6, 100\% cells showed bi-exponential decay.

At P9-11 ( $\mathrm{n}=30), 87 \%$ cells showed bi-exponential decay, 10\% showed mono-exponential and 3\% showed triexponential.

At P15-17 ( $\mathrm{n}=14), 71 \%$ cells showed bi-exponential decay, $7 \%$ showed mono-exponential and $22 \%$ showed triexponential.

At P21-24 (n=35), 54\% cells showed bi-exponential decay, and 46\% showed tri-exponential. 


\begin{tabular}{|c|c|c|c|c|c|}
\hline \multirow{2}{*}{ Leak conductance } & \multicolumn{5}{|c|}{ Dendrite length-Weighted decay $\tau$} \\
\cline { 2 - 6 } & $10 \mu \mathrm{m}$ & $20 \mu \mathrm{m}$ & $40 \mu \mathrm{m}$ & $80 \mu \mathrm{m}$ & No dendrite \\
\hline $62.5 \mu \mathrm{S} / \mathrm{cm}^{2}$ & $11.61 \mathrm{~ms}$ & $11.24 \mathrm{~ms}$ & $11.21 \mathrm{~ms}$ & $11.2 \mathrm{~ms}$ & $22.2 \mathrm{~ms}$ \\
$125 \mu \mathrm{S} / \mathrm{cm}^{2}$ & $11.28 \mathrm{~ms}$ & $11.04 \mathrm{~ms}$ & $10.75 \mathrm{~ms}$ & $10.4 \mathrm{~ms}$ & $14.35 \mathrm{~ms}$ \\
$250 \mu \mathrm{S} / \mathrm{cm}^{2}$ & $10.74 \mathrm{~ms}$ & $10.26 \mathrm{~ms}$ & $9.41 \mathrm{~ms}$ & $8.63 \mathrm{~ms}$ & $10.9 \mathrm{~ms}$ \\
$500 \mu \mathrm{S} / \mathrm{cm}^{2}$ & $9.7 \mathrm{~ms}$ & $9.0 \mathrm{~ms}$ & $8.0 \mathrm{~ms}$ & $6.5 \mathrm{~ms}$ & $4.9 \mathrm{~ms}$ \\
\hline
\end{tabular}

Table 3. Computer simulated EPSP weighted decay time constants using different dendrite lengths and leak conductance. 